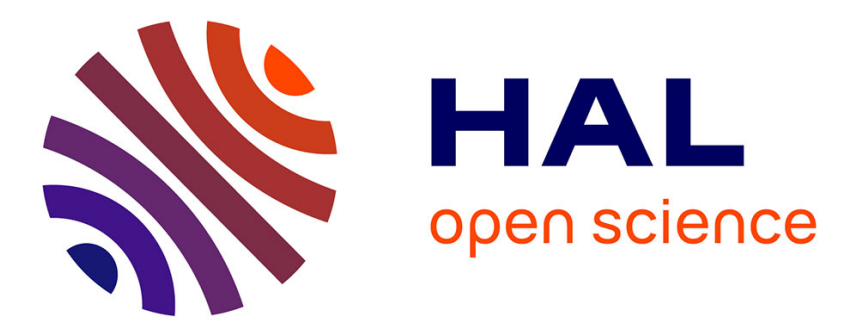

\title{
CUC Transcription Factors: To the Meristem and Beyond
}

Aude Maugarny, Beatriz Goncalves, Nicolas N. Arnaud, Patrick P. Laufs

\section{To cite this version:}

Aude Maugarny, Beatriz Goncalves, Nicolas N. Arnaud, Patrick P. Laufs. CUC Transcription Factors: To the Meristem and Beyond. Plant Transcription Factors, Elsevier, 2015, 9780128008546. 10.1016/B978-0-12-800854-6.00015-4 . hal-02795032

\section{HAL Id: hal-02795032 \\ https://hal.inrae.fr/hal-02795032}

Submitted on 5 Jun 2020

HAL is a multi-disciplinary open access archive for the deposit and dissemination of scientific research documents, whether they are published or not. The documents may come from teaching and research institutions in France or abroad, or from public or private research centers.
L'archive ouverte pluridisciplinaire $\mathbf{H A L}$, est destinée au dépôt et à la diffusion de documents scientifiques de niveau recherche, publiés ou non, émanant des établissements d'enseignement et de recherche français ou étrangers, des laboratoires publics ou privés. 


\section{5}

\section{CUC Transcription Factors: To the Meristem and Beyond}

\section{Aude Maugarny, Beatriz Gonçalves, Nicolas Arnaud, Patrick Laufs INRA, UMR1318, AgroParisTech, Institut Jean-Pierre Bourgin, Versailles, France}

\section{O U T L I N E}

15.1 Introduction

15.2 Evolution and Structure of NAM/CUC3

Proteins

15.2.1 The NAM/CUC3 Proteins are Part of the Large Plant-Specific Family of NAC

Transcription Factors

15.2.1.1 New Insights into the Origin of the NAC Family

15.2.1.2 Origin and Early Evolution of the NAM/CUC3 Family

15.2.1.3 Recent Evolution Within the NAM/CUC3 Family

15.2.2 NAM/CUC3 Protein Organization and Specific Domains

15.2.2.1 The Amino-Terminal NAC Domain 231

15.2.2.2 The Carboxy-Terminal Domain 232

15.3 NAM/CUC3 Genes Define Boundaries in

Meristems and Beyond

15.3.1 Identification of the NAM/CUC3 Genes:

Role in Boundary and Meristem Formation 234

15.3.1.1 Identification of NAM/CUC3 in

Petunia and Arabidopsis 234

15.3.1.2 Role in Other Dicots and Monocots 235

15.3.2 Role of CUC Genes in Other Meristematic

Territories

15.3.2.1 Axillary Meristems

15.3.2.2 Floral Organ Boundaries

15.3.2.3 Gynecium

15.3.2.4 Organ Abscission

15.3.3 Role of CUC Genes in Leaf Development

236

15.4 Multiple Regulatory Pathways Contribute to the Fine Regulation of NAM/CUC3 Genes 15.4.1 Hormonal Regulation of NAM/CUC3

Gene Expression
15.4.1.1 The Interplay between NAM/CUC3 Genes and Auxin 237

15.4.1.2 Brassinosteroids, New Regulators of CUC Expression

15.4.2 miR164 FineTunes NAM Gene Expression 238

15.4.2.1 miR164 Regulation is Essential for Shoot Development

15.4.2.2 Evolution and Specialization of the MIR164 Genes

15.4.2.3 Transcriptional Control of miR164 Expression

15.4.3 Transcriptional Regulation of NAM/CUC3

Expression

15.4.3.1 Transcription Factors Regulating CUC Expression During Embryogenesis

15.4.3.2 Transcription Factors Regulating CUC Expression During Axillary Meristem Formation

15.4.3.3 Transcription Factors Regulating NAM/CUC3 Expression During Leaf Development

15.4.3.4 Transcription Factors Regulating GOB Expression During Abscission 241

15.4.3.5 Regulation of CUC Expression by Chromatin Modifications

15.5 NAM/CUC3 Control Plant Development via Modifications of the Cellular Behavior 


\subsection{INTRODUCTION}

In 1996, Souer et al. reported the phenotypic characterization of a petunia mutant that fails to develop a shoot apical meristem (SAM) called "nam" (no apical meristem). The NAM gene is expressed in the boundaries of meristems and primordia, and the NAM protein shares a conserved $\mathrm{N}$-terminal domain with other proteins, suggesting that it is part of a novel class of proteins. Indeed, the following year, Aida et al. (1997) identified an Arabidopsis mutant with no apical meristem but with cotyledons fused along their edge resulting in a cup-like structure, hence named " $c u c$ " (cup-shaped cotyledon). This phenotype results from the combination of two mutations, one of which affects CUC2, a gene showing strong homology with the petunia NAM gene. These two papers began the story of the NAM/CUC3 genes and founded the basis for the NAM, ATAF1, ATAF2, and CUC (NAC) family of plant-specific transcription factors. Here, we retrace the phylogenetic and evolutionary context of NAM/CUC3 genes and review the important roles they play as boundary-defining actors during plant development. In particular, we discuss the mechanisms that regulate their expression patterns and how they affect plant development via their effects on cellular behavior.

\subsection{EVOLUTION AND STRUCTURE OF NAM/CUC3 PROTEINS}

\subsubsection{The NAM/CUC3 Proteins are Part} of the Large Plant-Specific Family of NAC Transcription Factors

\subsubsection{New Insights into the Origin of the NAC Family}

Together with ATAF1 and ATAF2, the petunia NAM and Arabidopsis CUC proteins are the founding members of the NAC family of plant-specific transcription factors (Aida et al., 1997). In an effort to trace the evolutionary origin of NAC proteins, Zhu et al. (2012) searched the full genome or expressed sequence tag (EST) data of 16 different species including eudicots, monocots, a lycophyte and a moss, chlorophytes, a red algae, and glaucophytes. Whereas a large number of NAC proteins have been identified in flowering plants (66-44, depending on the species) only 30 and 20 have been identified in Physcomitrella patens and Selaginella moellendorffii, respectively. This suggests that NAC proteins expanded as land plants evolved. Interestingly, no NAC proteins could be identified in the aquatic species analyzed, which suggests that NAC proteins may be specific to land plants. However, the analysis of $\mathrm{Zhu}$ and coworkers did not include any representatives of the charophytes which are thought to contain the sister group to land plants (Finet et al., 2010). Using Basic Local Alignment Search Tool (BLAST) searches we identified transcriptome shotgun assembly (TSA) sequences from the charophytes Coleochaete sp. (loci JO249122 and JO249294), Penium margaritaceum (locus JO233410), Chaetosphaeridium globosum (locus JO158096), and Nitella mirabilis (locus JV748667) whose putative translation yields proteins showing a conserved NAC domain (Figure 15.1). This observation strongly suggests that NAC proteins appeared before the transition from water to land, about 450 million years ago.

\subsubsection{Origin and Early Evolution of the NAM/ CUC3 Family}

The phylogeny of NAC proteins has been analyzed by several groups who often determined the position of NACs from a particular species in relation to Arabidopsis and rice NACs (e.g., Fang et al., 2008; Hu et al., 2010; Ooka et al., 2003; Pinheiro et al., 2009; Shen et al., 2009; Zhu et al., 2012). Results from these phylogenetic analyses show some variability: for instance, the number of subfamilies varies from 5 (Fang et al., 2008) to 21 (Zhu et al., 2012). Despite these variations, NAM/CUC3 proteins are often associated with the same group of proteins, although with a variable topology, forming an entire or part of a subfamily (Figure 15.2A).

Proteins that belong to the NAM/CUC3 family can be clearly divided into two clades: the NAM clade that includes the petunia NAM and Arabidopsis CUC1 and CUC2 proteins, and the CUC3 clade (Blein et al., 2008, Zimmermann and Werr, 2005). These two clades are based on the sequence of the NAC domain (Section 15.2.2.1), but also overlap with the presence/absence of a microRNA-binding site. Indeed, all NAM genes possess a binding site for the microRNA164 (miR164), whereas CUC3 genes do not. Members of these two clades can be found in eudicots, monocots, and early-diverging angiosperms such as Amborella trichopoda (Adam et al., 2011; Blein et al., 2008; Zimmermann and Werr, 2005; Vialette-Guiraud et al., 2011). On the other hand, gymnosperm genes possessing a miR164-binding site are not grouped within angiosperm NAM or CUC3 clades, rather they occupy a sister position to the combined NAM + CUC3 clade. This suggests that a unique NAM + CUC3 lineage regulated by miR164 was present in the last common ancestor of extant seed plants, and that a duplication event generated the NAM and CUC3 clades in the angiosperm lineage after its divergence from gymnosperms. In this scenario, loss of miR164 regulation would have occurred later in the CUC3 lineage (Vialette-Guiraud et al., 2011; Figure 15.2B).

\subsubsection{Recent Evolution Within the NAM/CUC3 Family}

Additional duplication events further complicated the phylogeny of NAM/CUC3 proteins in angiosperms. Such duplication events can either be recent, resulting in two closely related paralogs (such as the pea proteins 

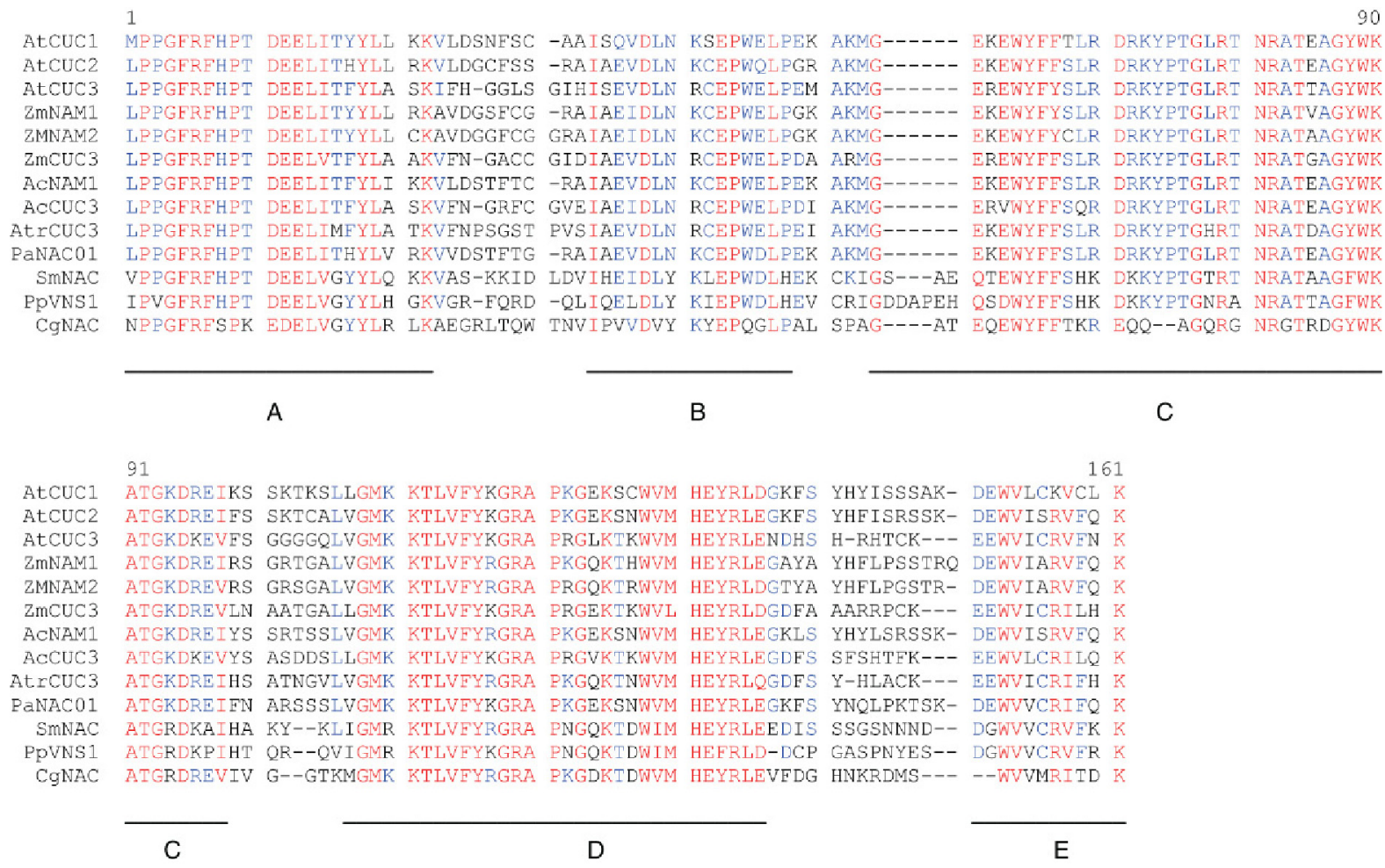

FIGURE 15.1 Alignment of the NAC domain of representatives of different plant groups showing five conserved subdomains named “A to E." At, Arabidopsis thaliana; Zm, Zea mays; Ac, Aquilegia coerulea; Atr, Amborella trichopoda; Pa, Picea abies; Sm, Selaginella moellendorffii; Pp, Physcomitrella patens; Cg, Chaetosphaeridium globosum. The alignment was produced using MultAlin (Corpet, 1988).

PsNAM1 and PsNAM2 that share 95\% identity) or more ancient leading to more divergent genes like the CUC1 and CUC2 proteins found in the Brassicaceae lineage (the Arabidopsis CUC1 and CUC2 proteins share only $50 \%$ identity mostly concentrated in the NAC domain). Indeed, phylogenetic analysis and reconstruction of genome duplication events suggest that two rounds of gene duplication followed by gene loss led to the distinct CUC1 and CUC2 lineages in Brassicaceae, which have partially divergent functions (Hasson et al., 2011, Vialette-Guiraud et al., 2011). Because the CUC1 and CUC2 lineages are specific to Brassicaceae and possibly other closely related Brassicales, the names "CUC1" and "CUC2" should be exclusively used for genes identified in these groups, while for other species "NAM" should be used. Here, we use "NAM/CUC3" when referring to genes belonging to either of the two clades, and "CUC" when referring specifically to Arabidopsis genes.

\subsubsection{NAM/CUC3 Protein Organization and Specific Domains}

NAM/CUC3 proteins, like other NAC transcription factors, can be subdivided into two main functional domains: an amino-terminal domain including the conserved NAC domain, and a more divergent carboxy-terminal domain (CTD; Duval et al., 2002; Taoka et al., 2004). Domain-swapping experiments between the NAC or CTD domains of CUC1, CUC2 and the more distantly related ATAF1 protein showed that the ability of the CUC1/2 proteins to promote in vitro adventitious shoot formation lies in their NAC domain, suggesting that this part of the CUC1 and CUC2 proteins determines their specific functions (Taoka et al., 2004).

\subsubsection{The Amino-Terminal NAC Domain}

This domain can be subdivided into five highly conserved regions (Figure 15.1) and has been implicated in the DNA-binding properties of several NAC proteins (e.g., Duval et al., 2002; Jensen et al., 2010). Most mutations disrupting CUC1 function fall into its NAC domain, thus highlighting its importance (Figure 15.3).

The DNA-binding mechanisms of NAC proteins have begun to be elucidated. ANAC019 and ANAC092 bind to a CGT[A/G] consensus site (Olsen et al., 2005; Tran et al., 2004; Xu et al., 2013). Binding affinity to this motif varies between NAC proteins (Jensen et al., 2010). Lindemose et al. (2014) showed that 12 NACs can be divided into three groups with different binding specificities. Two groups recognize variants of the previously identified CGT[A/G] target sequence while the third recognizes an unrelated motif. These groups largely match the phylogenetic differences between NAC proteins.

NAC proteins can form both homo- and heterodimers via interaction of their NAC domains, for which both the 
FIGURE 15.2 (A) Schematic phylogeny of the subgroup of Arabidopsis thaliana NAC proteins containing the CUC1, CUC2 and CUC3 proteins (adapted from Zhu et al., 2012). The genes targeted by the miR164 are indicated in red. (B) Schematic evolution of the NAM/CUC3 genes in seed plants. Members of the NAM + CUC3 clade are indicated in violet, members of the NAM clade are in blue, and members of the CUC3 clade are in red. Solid lines indicate lineages targeted by miR164 while dotted lines are lineages not targeted by miR164. (Vialette-Guiraud et al., 2011).
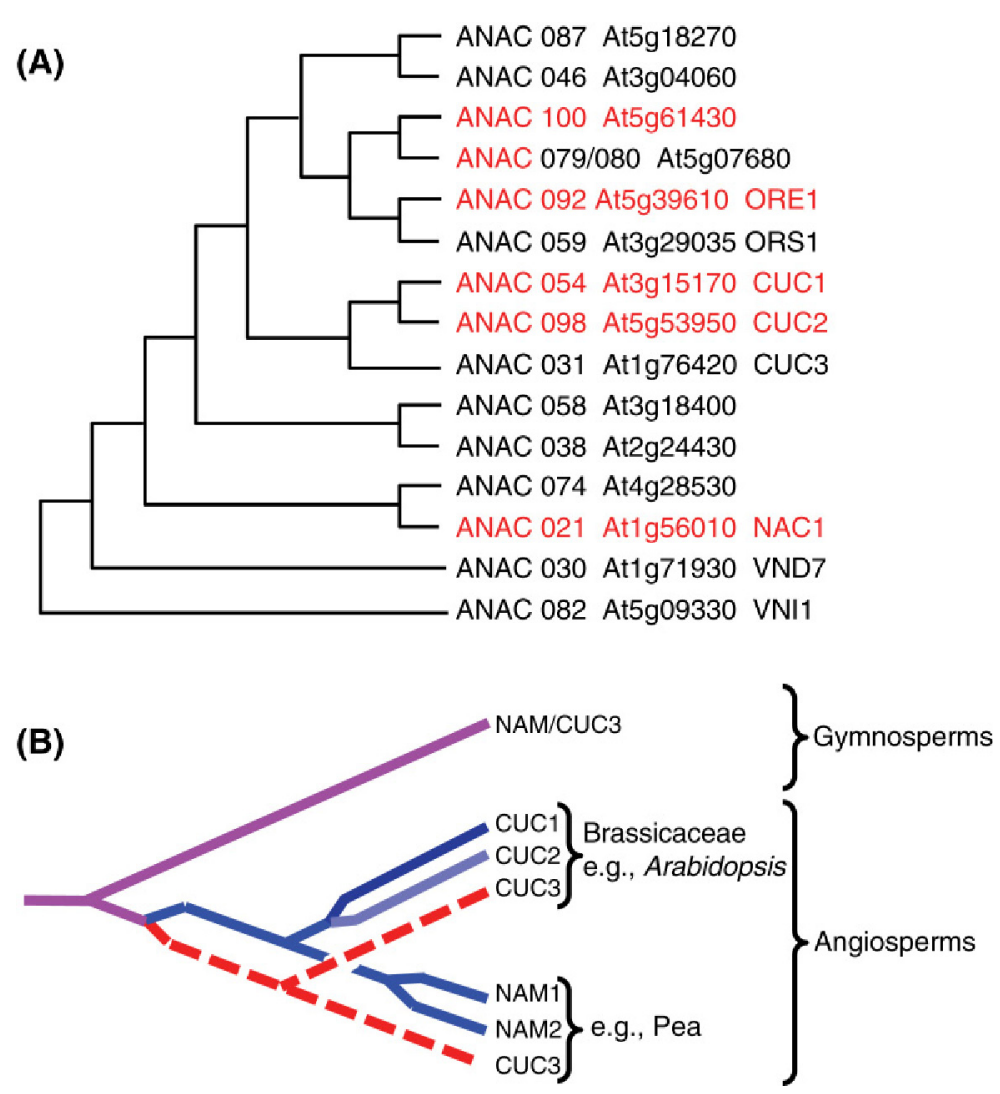

interacting surface and two essential salt-bridge-forming residues have been identified (Ernst et al., 2004; Olsen et al., 2005). NACs stably bind DNA as dimers by recognizing two palindromic binding sites, but a single binding site is also sufficient for NAC binding, both in vitro (Olsen et al., 2005) and in vivo (Tran et al., 2004; Xu et al., 2013). ANAC019 dimers can exist either in an open or a closed conformation (Welner et al., 2012). While the open conformation is predominant in solution, dimers mostly adopt a closed conformation when bound to DNA. Variation in dimer conformation may account for the recognition of DNA stretches with either single binding sites or a variable number of base pairs separating two binding sites.

The NAC domain of ANAC 019 contains a central twisted antiparallel $B$-sheet, which is packed between two $\alpha$ helices on both extremities (Ernst et al., 2004; Chapter 4). Part of this $B$-sheet formed by conserved WKATGTD amino acids protrudes into the major groove of DNA and interacts with the sugar/base region of DNA providing specificity to the recognition, while other parts interact with the DNA backbone potentially increasing affinity (Welner et al., 2012; Chapter 13). This mode of interaction shows similarities with those of plant WRKY and mammalian glial cells missing (GCM) transcription factors.

To date, no structure data on any of the NAM/CUC3 proteins nor their DNA binding sites have been determined. A recent study suggests that, like ANAC019 and other phylogenetically related proteins, NAM/CUC3 may recognize a TT[A/G]CGT[A/G] motif (Lindemose et al., 2014). However, because the WKATGTD residues that contribute to ANAC019 specificity are replaced by WKATGKD in NAM/CUC3 proteins, it is not clear how conserved the core binding site can be. It is therefore essential to determine the binding specificity of NAM/ CUC3 proteins experimentally.

\subsubsection{The Carboxy-Terminal Domain}

The CTD of NAM/CUC3 proteins is more variable than the NAC domain, but several small domains can be recognized. However, these domains are not all found in all NAM/CUC3 proteins and neither are they specific to these proteins, as they can be found in other NACs. Initially, Taoka et al. (2004) identified three domains called the V (TEHVSCFS), L (SLPPL), and W motifs (WNY) as well as a serine-rich domain, but further analyses identified additional domains (Adam et al., 2011; Larsson et al., 2012; Zimmermann and Werr, 2005; Figure 15.3). When fused to the GAL4 DNA-binding domain, the CTD of CUC1 and CUC2 proteins, like that of other NAC proteins, shows transcription activation in yeast cells and tobacco BY-2 cells (Taoka et al., 2004). Its serine-rich and W domains are necessary for transcriptional activity in yeast, while the $\mathrm{V}$ and $\mathrm{L}$ motifs are dispensable. The $\mathrm{W}$ motif is also important in planta as the strong cuc1-3 and weak cuc1-6 alleles affect this domain (Hibara et al., 2006; Takada et al., 2001; Figure 15.3). In contrast to the serine-rich and 

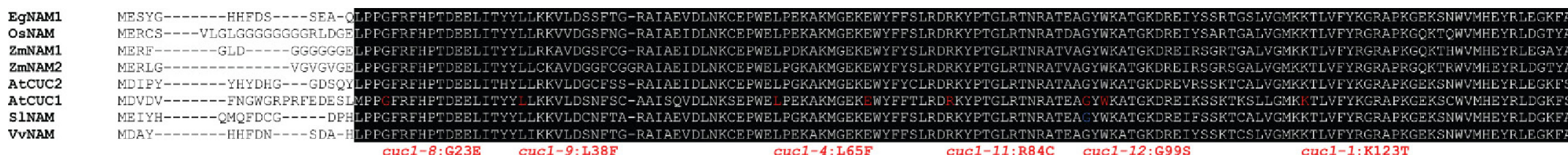

WIYYH-----QMQFDOG-

cuc1-8:G23E

cuc1-9: I38E

cuc1-4: L65F

cucI-IO: E75K

cuc1-12:G99S
cuc1-7; 101 Stop
Gob2:G95D

WWVMHE

DGKF SYHYI ISS S

OsNAM

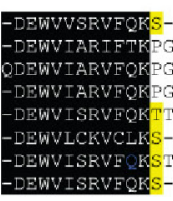

作

CGKKARVGLAGSHYSESTSUSPSAASLPP-------LFDSSPYG----AAA-AAGDRDSCSYE -

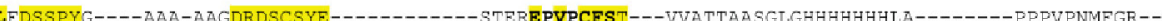

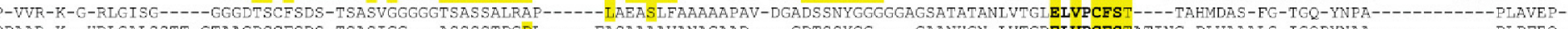

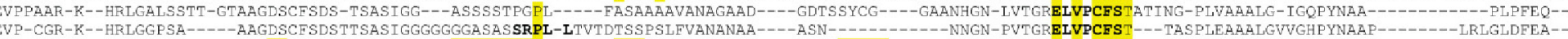

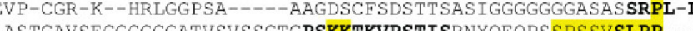
DSSCSYDSRSTHTHEN-PVGGRIVPCES

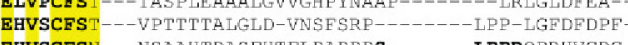

A.tCUC2

STGGGKK-RLSSSINMY

$-----\mathrm{k}----$

GobI: Q167Stop
-LTDPTTTLGY

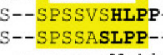

--I-
-Motif V-

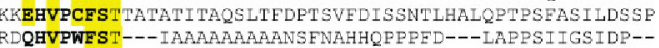

--Motif II

-----I-----

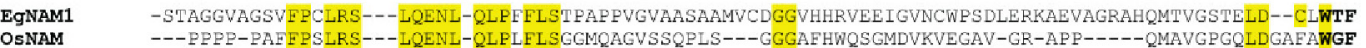

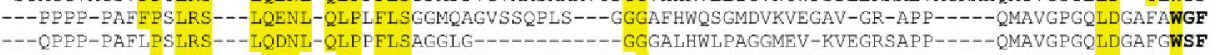

--PSPG-FVVPNLRS-LQVQDD-GGLPLFL SAA.AGGGMSSATLGIMGSLGGSLHCPPHAGMDVVKVEGRAAPP-----QMAVGPGLLDGAFAWG

VAFGQELDLGSSGQIDF---DA.AAAAFFPNLE SLPPTVLPPPPSEAMYGGGSPAVS---

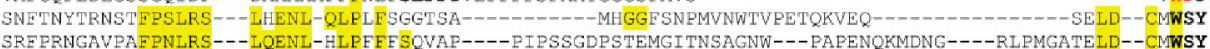

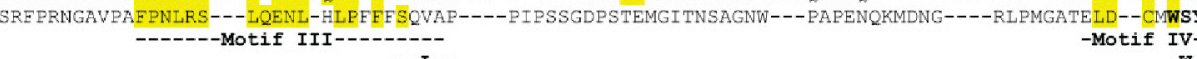

W-
cuc1-3: W306Stop

FIGURE 15.3 Alignment of the NAM proteins (adapted from Adam et al., 2011). The NAC domain is on a black background. In the CTD, conserved motifs, as defined in Adam et al. (2011; from I to IV), are on a gray background while those defined by Taoka et al. (2004) and Larsson et al. (2012); (domains K, L, V, and W) are in boldface. Mutations affecting either AtCUC1 or SINAM (also known as GOB) are indicated in red and blue, respectively. Eg, Elaeis guineensis; Os, Oriza sativa; Zm, Zea mays; At, Arabidopsis thaliana; Sl, Solanum lycopersicum; $\mathrm{Vv}$, Vitis vinifera. 
W domains that positively contribute to the transcriptional activity of CUC1/2 proteins, a hydrophobic region that contains the K domain (described by Larsson et al., 2012) represses CUC2 activity: deletion of this domain leads to a 14-fold increase in transcriptional activity in yeast (Taoka et al., 2004). Interestingly, the $\mathrm{K}$ domain is not only absent from monocot NAM proteins but also from CUC1, which correlates with a higher activity of CUC1 compared to CUC2 (Hasson et al., 2011).

\subsection{NAM/CUC3 GENES DEFINE BOUNDARIES IN MERISTEMS AND BEYOND}

As mentioned in the introduction, NAM/CUC3 genes were identified in genetic screens in petunia and Arabidopsis as arrested-development mutants showing seedlings with fused cotyledons. Here we present the mutant phenotypes, genetic studies, and expression pattern analysis that led to the characterization of the NAM/CUC3 functions during plant development.

\subsubsection{Identification of the NAM/CUC3 Genes: Role in Boundary and Meristem Formation}

\subsubsection{Identification of NAM/CUC3 in Petunia and Arabidopsis}

Petunia nam and Arabidopsis cuc1-cuc2 seedlings share similar phenotypes characterized by fused cotyledons and no SAM (Souer et al., 1996, Aida et al., 1997). This phenotype appears early on during embryonic development with an ectopic bulging at the central apical part of heart-shaped embryos. Simultaneous bulging within this region and at cotyledon primordia effectively leads to fusion of the two cotyledons (Figure 15.4A, B). Therefore, the role of CUC1/2 and NAM genes in cotyledon separation has been ascribed to inhibition of growth in the boundary region. Cotyledon fusion in these mutants is accompanied by a lack of embryonic SAM development. Indeed, presumptive SAM cells in cuc1cuc2 double-mutants do not express the meristem marker SHOOT MERISTEMLESS (STM; Aida et al., 1999). Together, these observations suggest that, in addition to their role in cotyledon separation, CUC1, CUC2, and NAM genes are also implicated in SAM initiation. Accordingly, these genes are expressed during embryogenesis in a region encompassing the presumptive SAM (Aida et al., 1999; Takada et al., 2001). In later stages, this expression disappears from the initiating SAM and becomes restricted to the boundaries between the developing cotyledons and the SAM (Figure 15.4G). This observation suggests that $C U C 1, C U C 2$, and NAM have an early role in separating cotyledons and specifying SAM initiation, and a later one separating the undifferentiated SAM from the differentiating cotyledons.
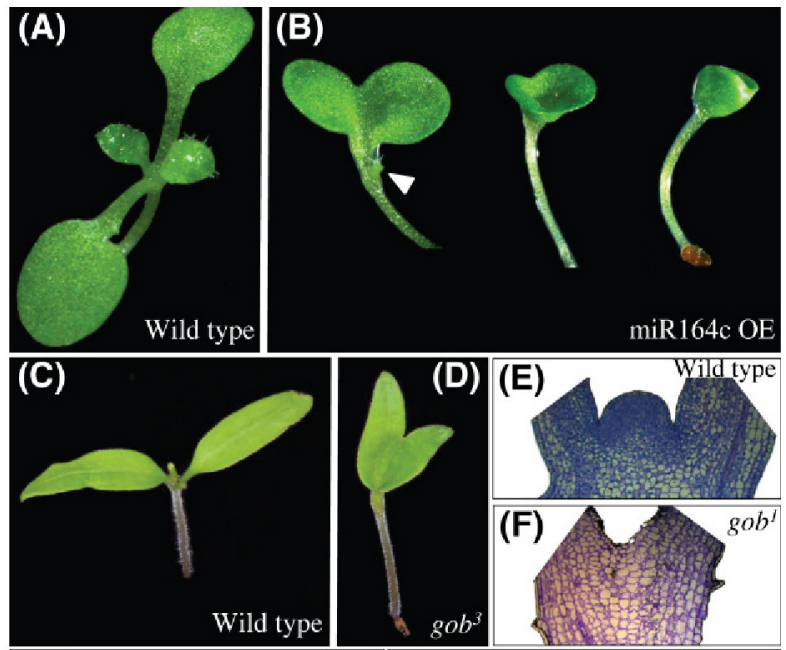

(G)

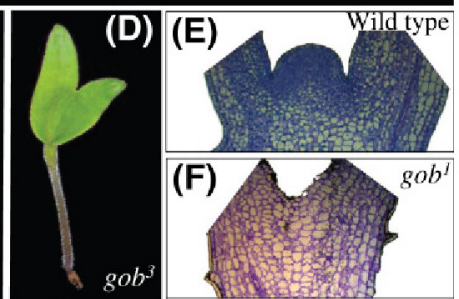

(H)
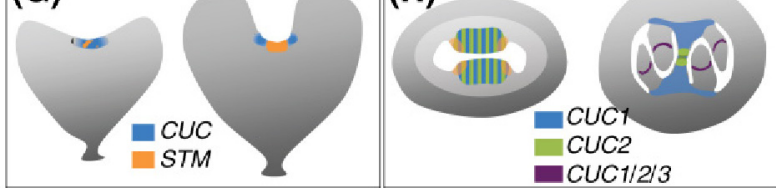

FIGURE 15.4 Mutant phenotypes and expression patterns of NAM/ CUC3 genes in Arabidopsis and tomato. (A) Wild-type Arabidopsis seedlings and (B) transgenic seedlings showing various degrees of cotyledon fusion phenotypes resulting from reduced expression of $\mathrm{CUC} 1 / 2$ due to overexpression of its regulator miR164. Weak phenotypes show partial cotyledon fusion and reduced meristematic activity (arrowhead points to young leaves) and strongly silenced lines show complete cotyledon fusion and no meristematic activity. (C) Tomato wild-type seedlings and (D) gob mutant seedlings showing partial cotyledon fusion. (E, F) The cotyledon fusion phenotype of gob mutants is accompanied by an absence of meristem that can be identified in the wild type as a bulge between cotyledon primordia. (G) The expression domain of CUC genes at the central apical region of heart-stage embryos (left) overlaps that of shoot apical meristem marker STM. At later stages (right) CUC expression is restricted to the boundary between cotyledon primordia and the meristematic zone. (H) CUC genes are expressed during gynecium development at the adaxial side (lighter gray at the left) of the medial region in the presumptive septum in a region encompassing the future placenta (in orange at the left). This expression is sustained at the medial ridge tips during septum development and eventual fusion. CUC genes are also expressed in the boundaries and at the base of ovule primordia and in a ring at the boundary between the nucellus and chalaza.

Much like in the embryo, CUC genes are expressed at a variety of frontier regions in the mature plant, such as the boundary between the apical meristem and leaf primordia, between the inflorescence and floral meristems, or even between different floral organs. Accordingly, regenerated shoots of cuc double-mutants show organ fusions at all these levels (Aida et al., 1997). Therefore, these genes have been classified as general regulators of organ separation, or, simply put, boundary genes.

While cuc1-cuc2 double-mutants show strong fusion phenotypes with no SAM initiation, single $c u c 1$ or $c u c 2$ mutants are phenotypically normal for the most part, with few showing incomplete cotyledon fusions that produce heart-shaped seedlings. The incomplete penetrance of 
single mutations and the overlap of CUC1 and CUC2 expression domains suggest that a certain degree of functional redundancy exists between these genes (Takada et al., 2001). The characterization of the CUC3 gene increased the degree of functional redundancy between CUC genes. Indeed, this paralog has overall similar expression patterns to CUC1 and CUC2 as well as additive phenotypic effects (Vroemen et al., 2003).

\subsubsection{Role in Other Dicots and Monocots}

Since the characterization of nam and cuc mutants in petunia and Arabidopsis, similar roles in boundary specification and organ separation have been revealed for NAM/CUC3 genes in other species. For example, nam mutants in Medicago truncatula have fused cotyledons and lack primary apical meristems (Cheng et al., 2012). In Antirrhinum majus, the CUPULIFORMIS (CUP) gene has been identified through its mutant phenotype, which presents strong organ fusion both at the embryonic and vegetative level (Weir et al., 2004). Despite strong defects in meristem initiation, cup mutants can produce secondary meristems at the hypocotyl. These develop severe fusions of leaves and floral organs as well as phyllotaxis perturbations. Overall, organ fusion defects in cup mutants are more severe than observed in Arabidopsis сuc1-cuc2, suggesting that the redundancy level between NAM/CUC3 paralogs can vary. Tomato (Solanum lycopersicum) goblet ( $g \circ b$ ) mutants show similar phenotypes of cotyledon fusion and SAM absence (Figure 15.4C-F; Berger et al., 2009; Blein et al., 2008; Brand et al., 2007). The role of NAM/CUC3 genes in monocots has not yet been functionally tested, but characterization of the maize ZmNAM1, ZmNAM2, and ZmCUC3 genes as well as the oil palm EgNAM1 and EgCUC3 genes showed that they have similar expression patterns to Arabidopsis homologs, with transcripts being found in meristematic tissues and in cells separating adjacent organs. Interestingly, small differences may exist between monocots and dicots: for instance, $\mathrm{ZmCUC3}$ is expressed later than $\mathrm{ZmNAM1/2}$ during maize embryo development whereas CUC3 is activated earlier than CUC1/2 in Arabidopsis (Zimmermann and Werr, 2005). Nevertheless, these proteins appear to have a conserved function, as oil palm homologs are capable of increasing leaf serration when ectopically expressed in Arabidopsis (for the role NAM/CUC3 plays in leaf development see Section 15.3.3) and restore organ fusion defects in cuc mutants (Adam et al., 2011).

\subsubsection{Role of CUC Genes in Other Meristematic Territories}

As full cup-shaped mutants usually lack a SAM, the study of their effect at the postembryonic level is dependent on the formation of escape or regenerated shoots. Studies of such regenerated shoots have allowed for additional roles of NAM/CUC3 genes during later vegetative and flowering stages to be characterized.

\subsubsection{Axillary Meristems}

Axillary meristems form near the shoot apex during vegetative and reproductive development at the axils of developing rosette and cauline leaves (Grbic and Bleecker, 2000). CUC1/2/3 transcripts have been detected in axillary meristems at the boundary between leaf primordia and the shoot apex, and cuc3 mutants fail to initiate axillary meristems in rosette leaf axils (Aida et al., 1999; Hibara et al., 2006; Ishida et al., 2000; Raman et al., 2008; Takada et al., 2001). This phenotype is greatly enhanced by the cuc 2 mutation but is not observed in other singlemutants or combination of mutants, suggesting that, although both CUC2 and CUC3 are required for axillary meristem specification, CUC3 contribution is greater (Hibara et al., 2006; Raman et al., 2008). Alternatively, plants expressing miR164-resistant variants of CUC1/2 genes form accessory axillary meristems (Raman et al., 2008). Collectively, these results show that CUC genes redundantly promote shoot meristem formation both during embryonic and postembryonic development.

\subsubsection{Floral Organ Boundaries}

Flowers of Arabidopsis cuc1-cuc2 double-mutants show strong organ fusions between sepals and stamens and also have fewer petals and stamens (Aida et al., 1997). Floral phenotypes in single-mutants are much less severe, suggesting once again a certain degree of functional redundancy between CUC genes (Hibara et al., 2006). Accordingly, CUC1/2/3 have mostly overlapping expression patterns in the boundaries between floral organs, both between organs of the same whorl and between different whorls (Hibara et al., 2006; Ishida et al., 2000; Takada et al., 2001; Vroemen et al., 2003). Similar to the way they function in the SAM, CUCs act at the boundaries of organ primordia suppressing cell proliferation and bulging, which allows for clean organ separation. The roles CUC1/2 play in floral organ number and separation are also dependent upon their regulation by miR164. Indeed, eep 1, a mutant allele of MIR164C, leads to the production of supernumerary petals in regions adjacent to normal organs, which is associated with an increase in CUC1 and CUC2 expression (Baker et al., 2005).

The role of NAM /CUC3 genes in floral organ patterning and separation also appears to be conserved across angiosperms. Floral organ fusions are observed in Medicago truncatula nam, tomato gob, and Antirrhinum cup mutants, with the corresponding genes being expressed at floral organ boundaries (Berger et al., 2009; Cheng et al., 2012; Weir et al., 2004). Interestingly, the expression of a miR164resistant variant of $S I G O B$ leads to the production of accessory organs mostly in the petal and carpel whorls, 
suggesting conservation of the miR164/CUC module during tomato flower development (Berger et al., 2009).

\subsubsection{Gynecium}

Arabidopsis CUCs are also expressed within carpel tissues and around developing ovules, suggesting they play a role in gynecium and ovule development (Galbiati et al., 2013; Ishida et al., 2000; Kamiuchi et al., 2014; Nahar et al., 2012; Takada et al., 2001; Vroemen et al., 2003). In Arabidopsis, gynecia are composed of two carpels that fuse along two opposing longitudinal medial ridges. The two medial ridge meristems form the placenta, a tissue with meristematic properties, which develops ovules and central outgrowths that fuse to form the septum. Gynecia that lack CUC activity fail to initiate medial ridge meristems resulting in severe septum fusion defects and fewer ovules (Ishida et al., 2000; Kamiuchi et al., 2014; Nahar et al., 2012). The early expression of CUC1/2 at presumptive medial ridges, the absence of meristem marker STM expression in the double mutant, and the enlargement of carpel margins in plants expressing miR164-resistant forms of CUC1 or CUC2 indicate that these genes act both to initiate medial ridge meristems and to maintain their meristematic state (Figure 15.4H; Kamiuchi et al., 2014). In some mutants, incipient medial ridge meristems are formed in an asymmetric fashion suggesting that $C U C 1 / 2$ are also required for proper positioning of meristems. In a more extreme case, miR164-dependent CUC2 misregulation leads to incomplete carpel fusion, as medial ridges are incompletely formed (Larue et al., 2009; Nikovics et al., 2006; Sieber et al., 2007). Several lines of evidence suggest CUC genes play a role in ovule development, notably the reduced number of ovules in cuc double-mutants and the expression of $C U C 1 / 3$ between ovule primordia and CUC1/2/3 between nucellus and chalaza (Aida et al., 1999; Ishida et al., 2000; Vroemen et al., 2003). Although, the exact mechanisms through which CUC genes regulate ovule development are still unknown, a recent model involving the integration of auxin signaling has been proposed (Section 15.4.1.1; Galbiati et al., 2013).

Other results are also suggestive of conservation of NAM/CUC3 roles in gynecium and ovule development across angiosperms. In Medicago truncatula, nam mutant carpel margins are incompletely fused and fewer ovules with altered embryo sac development are formed, leading to female sterility (Cheng et al., 2012). Antirrhinum cup mutants not only produce fewer ovules and/or fused ovules, they are also female sterile (Weir et al., 2004).

\subsubsection{Organ Abscission}

Abscission - the detachment of aged, mature, or diseased organs such as leaves and seeds - occurs in specific regions that display a set of characteristics reminiscent of meristematic tissues such as small cells with dense cytoplasms (Nakano et al., 2013). These abscission zones situated at key hinge regions share characteristics with boundaries. Indeed, in tomato, the $G O B$ gene and other genes known to promote meristematic identity in axillary meristems are expressed in the abscission zone.

\subsubsection{Role of CUC Genes in Leaf Development}

Arabidopsis leaves are simple with small serrations on their margins. While cuc2 mutants produce leaves with smooth margins, plants with increased CUC2 expression as a result of defective miR164 regulation show deeper and larger serrations than the wild type (Nikovics et al., 2006). cuc3 mutants also show reduced serrations, while CUC1, which is not expressed in leaves, plays no role in Arabidopsis leaf development. Whereas CUC2 acts early on with the onset of teeth, CUC3 is thought to act only at later stages to sustain teeth outgrowth (Hasson et al., 2011). Interestingly, chimeric constructs, where the CUC2 promoter drives the expression of CUC1 rescue normal leaf serration in $c u c 2$ mutants, also induce leaflet formation in genetic backgrounds lacking miR164. These results show that, even though CUC1 is not expressed in developing leaves, the CUC1 protein is partially functionally interchangeable with CUC2.

In species with compound leaves the role of NAM/CUC3 genes is extended to specify the boundaries between leaflets. Indeed, these genes are expressed at the boundaries of leaflet primordia, and their inactivation results in fused and fewer leaflets (Berger et al., 2009; Blein et al., 2008; Cheng et al., 2012; Wang et al., 2013). Alternatively, tomato plants expressing the gain-of-function miR164-resistant allele Gob4- $d$ produce deeply lobed leaflets (Berger et al., 2009). Altogether, these observations are suggestive of a conservation of the mechanisms controlling boundary specification between the apex and leaf primordia with different architectures.

\subsection{MULTIPLE REGULATORY PATHWAYS CONTRIBUTE TO THE FINE REGULATION OF NAM/CUC3 GENES}

Section 15.3 focused on nam/cuc3 mutant phenotypes and highlighted the precise expression patterns of these genes during development. NAM/CUC3 genes are expressed in narrow and discontinuous domains, often restricted to a few cells at the boundary between two outgrowing structures. Regulation of this expression pattern is essential for proper organ development as CUC overexpression leads to severe phenotypes (Hibara et al., 2006; Laufs et al., 2004). When CUC2 is uniformly expressed across the leaf margin instead of its discrete expression pattern at the teeth sinuses, a smooth leaf margin is formed in place of the typical serrated form (Bilsborough et al., 2011). 


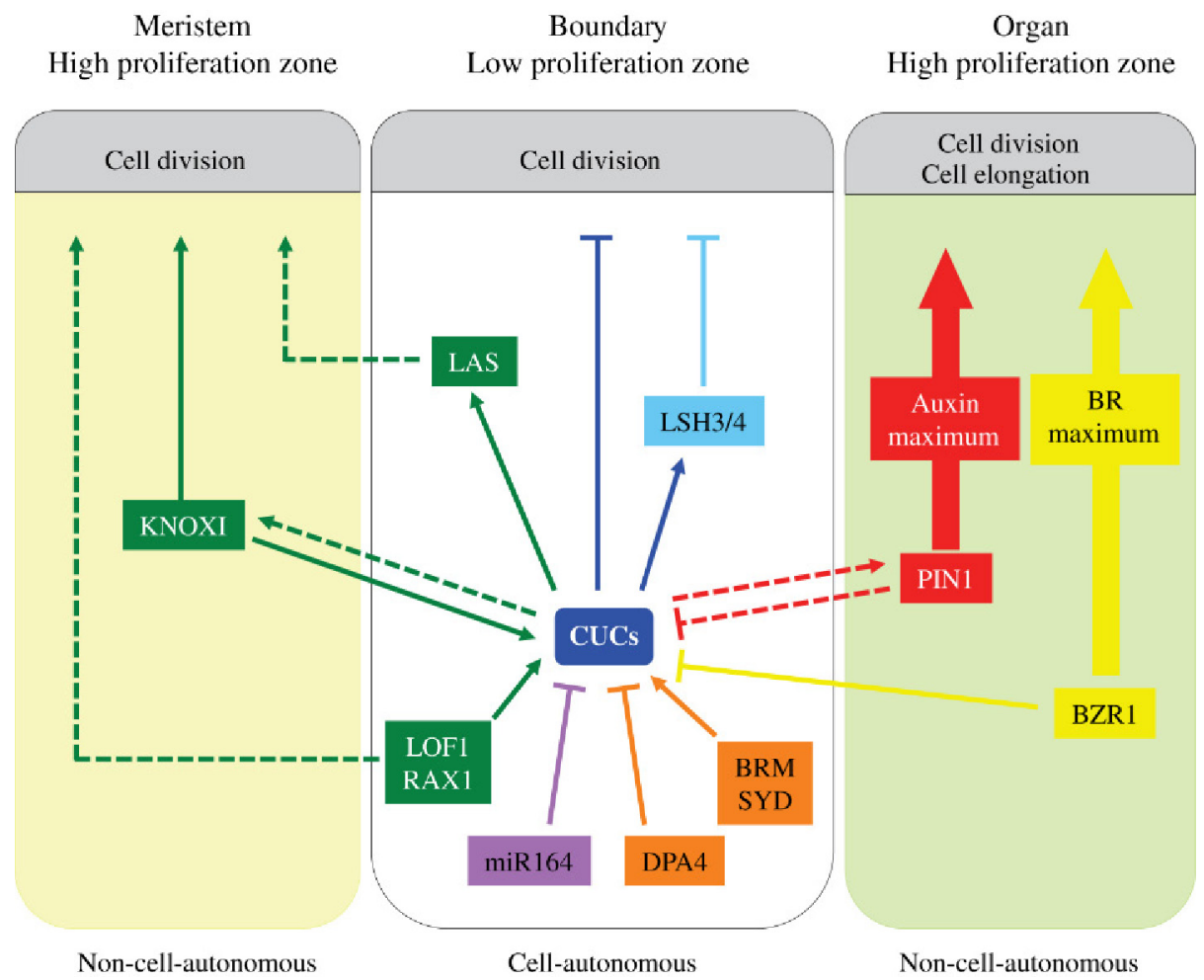

FIGURE 15.5 CUC regulatory network. CUC transcription factors are regulated by chromatin regulators such as BRM, SYD, and DPA4. CUC1 and CUC2 are negatively regulated by miR164. LOF1 and RAX1 induce CUCs during axillary meristem formation. BRs and auxin, which promote lateral organ proliferation, participate in the CUC discrete boundary expression pattern. BR modify BZR1 activity, which in turn negatively regulates CUCs. Auxin maxima, formed via a PIN1-dependent mechanism in growing primordia, restrict CUC expression to boundaries. In turn, CUCs act via a nonidentified mechanism dependent on PIN1 to modify auxin levels. KNOX genes, which are essential for meristem maintenance, induce CUC expression and activate KNOX expression in a feedforward regulatory loop as well. KNOX, LOF, RAX1, and LAS all contribute to maintaining the high division rate in meristematic zones. CUCs directly activate LSH3 and LSH4 in boundary cells. This complex regulatory network allows both the definition of the boundary by locally repressing growth and organ outgrowth, and meristem initiation and maintenance by promoting growth in a non-cell-autonomous manner. Solid arrows represent direct interaction; dashed arrows represent nonlocal genetic interactions.

This section discusses the factors that contribute to establishing the precise expression patterns of NAM/CUC3 genes throughout plant development (Figure 15.5). First, we discuss how hormonal regulation shapes NAM/CUC3 expression. Then, we consider the role of miR164 in the posttranscriptional regulation of NAM genes. Finally, we describe NAM/CUC3 transcriptional regulation.

\subsubsection{Hormonal Regulation of NAM/CUC3 Gene Expression}

\subsubsection{The Interplay between NAM/CUC3 Genes and Auxin}

Numerous works suggest that CUC2 expression is repressed by PIN1-generated auxin maxima. The PINFORMED1 (PIN1) gene encodes an auxin efflux carrier that has a polar distribution within the cell thus contributing to differential auxin accumulation in Arabidopsis. In developing embryos, PIN1-dependent auxin maxima induce cotyledon formation (Friml et al., 2003). In pin1 mutants, the CUC1 expression domain is extended to the entire apical region whereas CUC2 is expressed in patches restricted to the center and sides of the embryo (Aida et al., 2002). The PINOID (PID) gene encodes a serine/threonine kinase that acts as a positive regulator of PIN1-mediated polar auxin transport. pin1-pid doublemutant embryos completely lack cotyledons and show broad expression of CUC1 and slight enlargement of the CUC2 expression domain. Additionally, pin1-pid-cuc1 triple-mutants form small cotyledons which suggests that ectopic expression of CUC1 in pin1-pid embryos is responsible for the absence of cotyledons (Furutani et al., 2004). pasticcino1 (pas1) mutants show defective cotyledon development and associate altered membrane localization of PIN1 with an enlargement of the domain expressing CUC2 (Roudier et al., 2010). Overall, these results indicate that PIN1-mediated auxin transport is necessary to regulate CUC1/2 expression in the embryo.

During postembryonic development, pin1 mutants produce a naked inflorescence (Okada et al., 1991). In similarly to what as happens in the embryo, primordia positioning in the SAM is determined by PIN1-driven auxin maxima (Reinhardt et al., 2003). In pin1 mutants, CUC2 expression is enlarged forming a circle around 
the inflorescence SAM (Vernoux et al., 2000). Moreover, live imaging experiments suggest that CUC2 expression is downregulated in tissues where convergent PIN1 polarities are expected to accumulate high auxin levels (Heisler et al., 2005). Together, these results suggest that CUC2 expression in the SAM is inhibited by PIN1-generated auxin activity maxima. As explained in Section 15.3.2.1, CUC2 genes redundantly promote axillary meristem formation (Raman et al., 2008). Two articles suggest that an auxin minimum is required for axillary meristem formation in Arabidopsis and tomato (Wang et al., 2014a; Wang et al., 2014b). Although this has not been tested, this auxin minimum could allow CUC expression thus inducing axillary meristem formation.

pin1 Arabidopsis mutants form leaves that lack serrations. PIN1-mediated auxin response foci at the leaf margin are interspaced with regions showing high CUC2 and CUC3 expression (Hasson et al., 2011; Hay et al., 2006; Nikovics et al., 2006). Auxin treatments are able to abolish expression of a CUC2 reporter in leaf primordia, suggesting that auxin negatively regulates CUC2 expression during simple leaf development (Bilsborough et al., 2011).

As mentioned in Section 15.3.2.3, CUC1 and CUC2 are involved in carpel margin meristem initiation required for ovule initiation. In this context, MONOPTEROS (MP) is expressed in a similar pattern to CUC1 and CUC2. Moreover, in mp mutants, CUC1 and CUC2 expression is reduced in inflorescences and leaves. Chromatin immunoprecipitation (ChIP) experiments have established that MP directly binds CUC1 and CUC2 genomic regions (Galbiati et al., 2013). These results strongly suggest that MP positively regulates $C U C 1$ and $C U C 2$, providing a molecular link between auxin signaling and CUC genes. However, these results are difficult to reconcile with data obtained in the embryo where CUC1 expression domain is enlarged in $m p$ mutant embryos (Aida et al., 2002), indicating that $M P$ negatively regulates $C U C 1$ expression in the embryo. Moreover, it is surprising that an auxin response factor would positively regulate $C U C$ expression when in most organs auxin maxima negatively regulate CUC expression.

To date, it is not clear to what extent the relationship between auxin and CUC genes identified in Arabidopsis is conserved. In Cardamine hirsuta, a close relative of Arabidopsis with compound leaves, it is not known whether ChCUC expression is controlled by polar auxin transport as in Arabidopsis. Interestingly, the expression of $G O B$ in tomato is not modified upon auxin treatment. Moreover, ENTIRE, an auxin-response repressor, acts on leaf dissection in a parallel pathway independent of $G O B$ (Ben-Gera et al., 2012; Berger et al., 2009). Alternatively, auxin-induced downregulation of NAM genes seems to be a general feature during embryonic and postembryonic development, and some evidence points to conservation of this role. Indeed, in the gymnosperm Picea abies a NAM/CUC3 ortholog is also regulated by polar auxin transport (Larsson et al., 2012).

A recent work reported a link between cytokinins and CUCs (Li et al., 2010). A line overproducing cytokinins produces more flowers, a phenotype that is dependent on CUC2 and CUC3 overexpression. Moreover, in the cytokinin receptor ahk2-ahk3 double-mutant, CUC1 and CUC2 expression is strongly reduced, suggesting that cytokinin signaling promotes CUC expression. Interestingly, there is increasing evidence that cytokinin signaling controls polar auxin transport (Marhavy et al., 2014). Therefore, further investigations are required to determine whether regulation of CUC genes by cytokinins is mediated by auxin.

\subsubsection{Brassinosteroids, New Regulators of CUC Expression}

Brassinosteroids (BRs) are plant steroid hormones that regulate cell proliferation and other developmental processes (Kim and Wang, 2010). They act through a complex signaling pathway that leads to activation of two transcription factors, BZR1 and BES1, which in turn modify the expression of over 1000 genes.

Recent findings suggest a link between BRs and CUC genes. Plants with increased BR content or signaling show axillary shoot, stamen, and cotyledon fusions, reflecting abnormal boundary establishment (Gendron et al., 2012). Alternatively, mutants with reduced biosynthesis or sensitivity to BRs have deeper axillary separations and form ectopic boundaries. This suggests that low BR signaling is sufficient and necessary for proper boundary formation. Genetic and pharmacological experiments show that low BR signaling induces CUC expression in the SAM, whereas high BR signaling inhibits it. Additionally, ChIP experiments indicate that BZR1 strongly binds the CUC3 promoter suggesting direct regulation. Overall, these results indicate that BR signaling negatively regulates $C U C$ gene expression.

\subsection{2 miR164 FineTunes NAM Gene Expression}

miR164 was among the first identified plant miRNAs. In Arabidopsis, it is encoded by three loci, MIR164A, B, and $C$. It regulates the expression of six transcription factors of the NAC family: CUC1 and CUC2, NAC1 which is known to regulate lateral root induction, ORESARA1 (ORE1) which controls leaf senescence, and two uncharacterized NACs (At5g61430 and At5g07680; Schwab et al., 2005).

\subsubsection{1 miR164 Regulation is Essential for Shoot Development}

miR164 controls inflorescence and floral development. Plants expressing CUC1 or CUC2 miR164-resistant variants 
show extra petals and enlarged sepal boundaries (Laufs et al., 2004; Mallory et al., 2004). Another CUC2 miR164resistant allele has shorter and wider siliques with tissue projections along the valve margins (Larue et al., 2009). Accordingly, early extra petals1 (eep1), a mir164c mutant, also presents extra petals and defects in carpel fusion (Baker et al., 2005). This indicates MIR164C plays a role in regulating CUC1 and CUC2 during flower development. A similar role has been proposed for SlmiR164 in tomato, in which expression of a SlmiR164-resistant GOB variant results in extra petals and ectopic carpels (Berger et al., 2009). Expression of miR164-resistant CUC2 leads to modified phyllotaxy compared to wild type (Peaucelle et al., 2007), as also observed in the mir164abc triplemutant (Sieber et al., 2007). Strikingly, in both genotypes, the formation of primordia in the meristem appears to be normal. Taken together, this reveals that phyllotaxy is postmeristematically maintained via miR164-dependent negative regulation of CUC2.

miR164 also regulates leaf development. Both mir164a Arabidopsis mutants and CUC2 miR164-resistant lines present leaves with deeper serrations than the wild type. Moreover, MIR164A is expressed in leaf margin sinuses in a pattern overlapping CUC2 expression (Nikovics et al., 2006). Thus, in Arabidopsis, MIR164A regulates the level of CUC2 expression, which in turn governs the level of leaf serration. Interestingly, quantitative trait locus (QTL) mapping has revealed a single nucleotide polymorphism in MIR164A miRNA* which modifies MIR164A biogenesis and drastically reduces its accumulation (Todesco et al., 2012). This indicates that natural variation in MIR164A maturation can contribute to leaf serration polymorphism. In the compound leaves of tomato, the $G O B$ miRNA-resistant allele, Gob- $4 d$, harbors leaflets with deeper and wider lobes than the wild type, whereas gob mutants show smooth fused leaflets (Berger et al., 2009).
In contrast to Arabidopsis, GOB and SIMIR164 show complementary expression profiles and the $G O B$ expression pattern becomes wider in the Gob- $4 d$ allele. This suggests, that SlmiR164 defines the sharp domain of the GOB expression pattern rather than controling its expression level as in Arabidopsis.

miR164 controls axillary meristem development. Expression of CUC1 or CUC2 miR164-resistant variants leads to the formation of accessory buds in leaf axils, a phenotype also observed in mir164abc mutants. Concurrently, MIR164A and MIR164C are expressed in the boundary between the leaf primordium and the SAM, from where the axillary meristem subsequently emerges (Raman et al., 2008). Overall, CUC1 and CUC2 mRNA cleavage by miR164 is required to negatively regulate the formation of accessory buds in leaf axils.

These results establish CUC1/2-miR164 as a conserved genetic module that is recruited multiple times during the evolution of aerial organs (Figure 15.6). Moreover, miR164 plays a crucial role in regulating $N A C 1$ during lateral root induction (Guo et al., 2005) and inhibiting ORE1 expression during leaf senescence (Kim et al., 2009). miR164 is therefore an important regulator of plant development (Pulido and Laufs, 2010). Interestingly, miR164 does not seem to regulate its targets always in the same manner: while it regulates the timing of ORE1 expression, it regulates the $G O B$ expression pattern spatially during tomato leaf development and controls the level of CUC1 and CUC2 expression during flower and leaf development in Arabidopsis.

\subsubsection{Evolution and Specialization of the MIR164 Genes}

miR164 is found in dicots, monocots, and gymnosperms, indicating that, much like its target NAC genes, it was likely present in the last common ancestor of

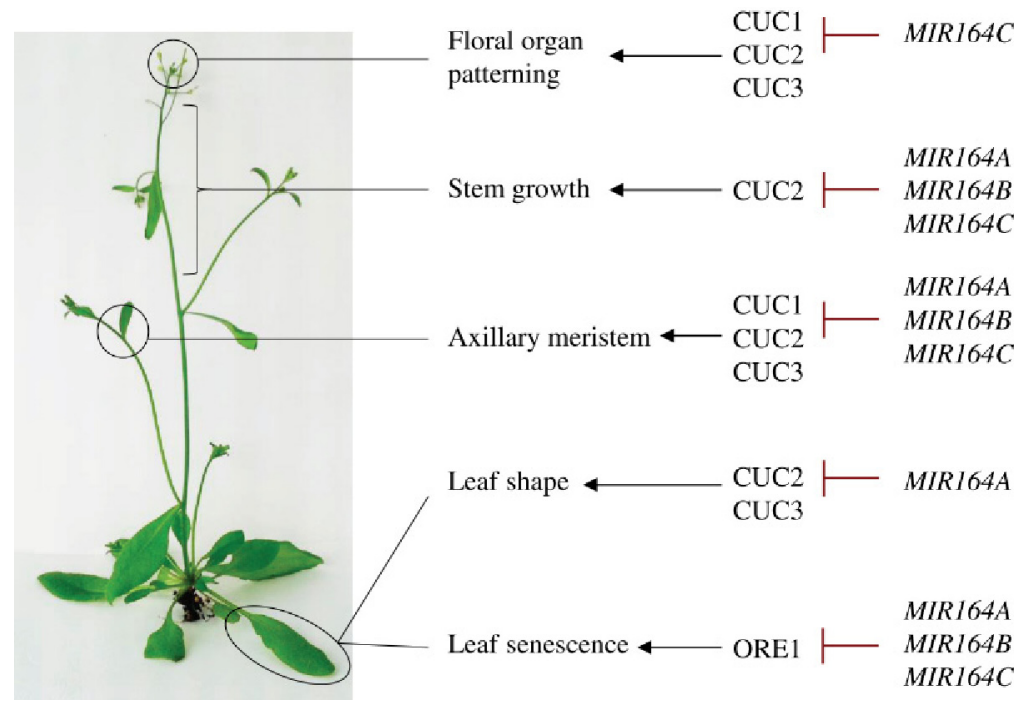

FIGURE 15.6 CUC/miR164, a genetic module essential for plant shoot development. The roles played by each CUC (and the related NAC gene, ORE1) and MIR164 genes during Arabidopsis development are indicated. 
gymnosperms and angiosperms (Section 15.2.1.2; Axtell and Bartel, 2005). Multiple genes code for miR164: 3 in Arabidopsis but up to 12 in soybean. Mature miR164 genes encoded by different members can be identical, such as in soybean, or show small sequence variations as in Arabidopsis in which mature miR164c differs by one nucleotide from mature mir164a or mir164b. An evo-devo study of the MIR164 family suggests that two lineages were present in the last common ancestor of extant angiosperms: a B clade containing the Arabidopsis MIR164B gene whose members tend to be highly expressed in roots; and another clade whose members, such as the Arabidopsis MIR164A and $C$ genes, tend to be less expressed in roots than in other tissues (Jasinski et al., 2010).

In some developmental processes, the three Arabidopsis MIR164 genes seem to be functionally redundant. For instance, $m i R 164 a, m i R 164 b$, and $m i R 164 c$ act redundantly to downregulate CUC2 expression during the postmeristematic maintenance of phyllotaxy (Sieber et al., 2007). In contrast, MIR164C plays a more important role during floral development than the two others (Sieber et al., 2007), while MIR164A is the negative regulator of CUC2 that controls leaf shape (Nikovics et al., 2006). The extent to which each MIR164 gene regulates different developmental processes varies and is likely to result from differences in their expression patterns.

\subsubsection{Transcriptional Control of miR164 Expression}

Transcription factors of the plant-specific TCP family (TEOSINTE BRANCHED/CYCLOIDEA/PROLIFERATING CELL FACTOR) are well known for the role they play in regulating developmental processes. They are divided into two classes (Martin-Trillo and Cubas, 2009; Chapter 16). In particular, class II CINCINNATA-like (CINlike) genes redundantly regulate cell proliferation and promote differentiation during leaf development. Plants expressing TCP3-EAR, a fusion with the EAR repression domain, have rosette leaves with exaggerated serrations and lobed cotyledons with ectopic shoot meristems (Koyama et al., 2007). CUC genes are overexpressed in these plants and miR164 accumulation is decreased. Moreover, cuc1 and cuc2 mutations suppress the TCP3$E A R$ phenotype, indicating that it mainly results from increased CUC expression. TCP3 has been found to directly activate MIR164A transcription (Koyama et al., 2010). Interestingly, some class I TCP members also regulate CUC expression (Uberti-Manassero et al., 2012). Thus, TCPs appear to be positive regulators of miR164 and indirect inhibitors of CUC expression.

Auxin regulates CUC expression both directly (Section 15.4.1.1) and indirectly via modification of miR164 levels. Indeed, auxin treatments can induce miR164 expression in roots (Guo et al., 2005), and some mutants with disrupted auxin signaling show enhanced leaf serration due to reduced MIR164A expression (Bilsborough et al., 2011). Thus, auxin regulates miR164 levels during root and leaf development.

miR164 expression is regulated by ethylene during leaf aging (Kim et al., 2009). In the ethylene insensitive 2 (ein2) mutant, no reduction of miR164 levels is observed, which suggests that EIN2 is required for MIR164 downregulation. EIN3 acts downstream of EIN2 and binds to MIR164A, MIR164B, and MIR164C promoters to repress their activity (Li et al., 2013). Overall, ethylene negatively regulates miR164 levels by activating EIN2 which in turn promotes EIN3 transcriptional repression activity.

Interestingly, all three MIR164 genes are marked with H3K27me3 repressive histone modification during leaf development (Lafos et al., 2011), suggesting that modification of chromatin dynamics also contributes to their regulation.

During floral development, a $\mathrm{C}_{2} \mathrm{H}_{2}$ zinc finger transcriptional repressor named RABBIT EARS (RBE) is specifically required for proper formation of secondwhorl boundaries (Krizek et al., 2006). rbe mutants show fused sepals and aberrant petals, which recapitulate the floral phenotype of $c u c 1-c u c 2$ double-mutants. RBE directly binds to the MIR $164 \mathrm{C}$ promoter, negatively regulating its activity in floral boundaries. Moreover, genetic analyses reveal that RBE negatively regulates MIR164B expression while activating MIR164A expression in floral buds (Huang et al., 2012). Thus, RBE would differentially regulate the expression of MIR164 genes during floral development, promoting their functional differentiation.

\subsubsection{Transcriptional Regulation of NAM/CUC3 Expression}

\subsubsection{Transcription Factors Regulating CUC Expression During Embryogenesis}

Class I KNOTTED-like homeobox genes (KNOXI) that code for homeodomain transcription factors are essential for SAM initiation and maintenance (for reviews see Hamant and Pautot, 2010; Hay and Tsiantis, 2009; Chapter 14). Plants mutated in the KNOXI gene STM lack a SAM and show reduced CUC1 and CUC3 expression, which is restricted to a stripe in the center of the boundary between two cotyledons (Takada et al., 2001; Vroemen et al., 2003). CUC2 expression is even more modified in stm embryos, being limited to small spots at variable positions between developing cotyledons (Aida et al., 1999). Thus, STM regulates CUC expression contributing to its localization at the center of the embryo. Alternatively, the absence of CUC downregulation in the center of the embryo could also be attributed to the lack of meristematic cells in the stm mutant. Spinelli et al. (2011) demonstrated that inducing STM expression activates CUC1 transcription in a direct manner since induction is maintained in the 
presence of a translational inhibitor. A binding site for STM in the CUC1 promoter has been identified and validated in vitro, in yeast, and in planta. Overall, this indicates that STM directly induces CUC1 expression.

Besides STM, there are other KNOXI genes that contribute to the establishment and maintenance of the SAM. Notably, their inactivation aggravates the phenotype of a weak stm allele, stm-2. For example, knat6-1-stm-2 doublemutants show no SAM and strong cotyledon fusion compared with stm-2. Although CUC3 expression is not altered in knat6 mutants, it is completely lost in knat6-1-stm-2 double-mutants indicating that KNAT6 and STM redundantly contribute to CUC3 activation (Belles-Boix et al., 2006).

In addition to KNOXI proteins the homeobox transcription factor WUSCHEL (WUS) also contributes to stem cell maintenance (Chapter 14). Although there is no evidence to suggest that WUS regulates CUC genes, other members of the same WUSCHEL-RELATED HOMEOBOX (WOX) clade control CUC expression in the cotyledon boundary. wox2 stimpy-like (stpl/wox8) double-mutants show partial cotyledon fusion, which correlates with asymmetrical CUC2 and CUC3 expression at one side of the embryo (Lie et al., 2012). Conversely, CUC1 expression in some embryos is expanded in the protodermal layer. Overall, WOX2 and STPL differentially regulate CUC genes, restricting CUC1 expression and allowing symmetrical expression of CUC2 and CUC3.

\subsubsection{Transcription Factors Regulating CUC Expression During Axillary Meristem Formation}

Two independent groups identified three genes coding for MYB domain transcription factors - REGULATOR OF AXILLARY MERISTEM 1 (RAX1), RAX2, and RAX3 - which are redundantly required for early induction of axillary meristems in Arabidopsis (Keller et al., 2006; Muller et al., 2006). Like the CUC genes, RAX1 and RAX3 are expressed in the axils of leaf primordia. Interestingly, in situ hybridizations show that CUC2 expression in rax 1 is missing at the exact position of a future axillary meristem, indicating that RAX1 induces local CUC2 expression to promote axillary meristem formation (Keller et al., 2006).

Like RAX1-3 genes, LATERAL ORGAN FUSION1 (LOF1) also encodes a MYB domain transcription factor involved in axillary meristem formation and expressed in leaf axils. lof1 mutants show reduced expression levels of CUC1/2/3 and RAX1 that could be indirectly mediated by changes in RAX1 activity (Lee et al., 2009). Overall, LOF1 and RAX1 are transcription factors that act upstream of CUC genes during axillary meristem formation.

\subsubsection{Transcription Factors Regulating NAM/CUC3 Expression During Leaf Development}

Besides their central role in meristem formation, KNOXI genes are also involved in the development of most compound leaves (Blein et al., 2010; Chapter 14). KNOXI expression is initially downregulated both in simple and compound incipient leaf primordia. Such downregulation is permanent in species with simple leaves, whereas it is transient in primordia of compound leaves, being reactivated later during primordia development (Bharathan et al., 2002). In Cardamine hirsuta, the expression of KNOXI genes is required for leaflet formation and their overexpression leads to more leaflets and deeper serrations (Hay and Tsiantis, 2006). KNOXI overexpression increases CUC expression, while silencing CUC genes in plants overexpressing KNOXI suppresses their phenotype, indicating that KNOXI genes promote leaflet formation by activating CUC expression (Blein et al., 2008).

Although observed in many species, the reactivation of KNOXI genes during compound leaf development is not a general mechanism. Instead, some Fabacea show activation of UNIFOLIATA, an ortholog of the Arabidopsis LEAFY ( $L F Y)$ gene, which controls leaflet formation in these species (Hofer et al., 1997). In Pisum sativum, the uni mutant forms simple smooth leaves where neither NAM nor CUC3 expression could be detected (Blein et al., 2008). Interestingly, CUC2 has been shown to be a possible target of LFY in the Arabidopsis inflorescence (Winter et al., 2011). All in all, UNI/LFY could be a positive regulator of NAM/CUC3 expression.

\subsubsection{Transcription Factors Regulating GOB Expression During Abscission}

Two MADS box domain transcription factors, JOINTLESS and MACROCALYX (MC), promote abscission zone formation during tomato fruit development (Nakano et al., 2012). Transcriptional studies on plants misexpressing JOINTLESS or MC show that GOB expression is probably positively regulated by the JOINTLESS /MC heterodimer (Nakano et al., 2012). Another gene induced by the JOINTLESS/MC heterodimer is the AP2/ERF transcription factor ETHYLENE RESPONSE FACTOR 52 (SIERF52). Plants with reduced SIERF52 levels are impaired when pedicel abscission is activated and present reduced $G O B$ expression, indicating that SIERF52 is also a positive regulator of $G O B$ expression (Nakano et al., 2014). Overall, this designates JOINTLESS/MC as early activators of GOB expression and SIERF52 as a late $G O B$ activator during fruit abscission.

\subsubsection{Regulation of CUC Expression by Chromatin Modifications}

Gene expression regulation depends not only on the presence of transcription factors that bind to specific promoter domains but also on chromatin availability to transcription factors. The chromatin dynamic is regulated by nucleosome-modifying enzymes that catalyze histone and DNA-covalent modifications as well as chromatin-remodeling complexes that remodel histone 
octamers/DNA interactions. Switch/sucrose nonfermentable (SWI/SNF) complexes are chromatin-remodeling factors conserved between yeast, mammals, and plants. Remodeling SWI/SNF complexes are recruited to promoters and regulate the accessibility of binding sites to transcription factors (Jerzmanowski, 2007).

In an enhancer screen of the cuc2 cotyledon fusion phenotype, three mutations in the BRAHMA (BRM) gene were identified. BRM is an adenosine triphosphatase (ATPase) of the SWI2/SNF2 family (Kwon et al., 2006). A mutation in another SWI2/SNF2 member, splayed (syd), also enhances the cotyledon fusion phenotype of $c u c 1$ and cuc3 mutants. Real time polymerase chain reaction (RT-PCR) and $\beta$-glucuronidase gene (GUS) reporter analyses established that $B R M$ positively regulates the expression of the three CUC genes, and that SYD induces CUC2 expression. This result indicates that general regulators of gene expression are also required for proper CUC expression.

Among factors regulating the chromatin dynamic are the modifying enzymes of histone octamers. These enzymes catalyze posttranslational modifications of histones, thus changing their interaction with DNA. One of the bestcharacterized histone modifications is the trimethylation of histone 3 on lysine 27 (H3K27me3), which leads to chromatin compaction and transcriptional repression. This mark is deposited by Polycomb group (PcG) proteins assembled in the Polycomb repressive complex 2 (PRC2). H3K27me3 is subsequently recognized by PRC1, which mediates locus repression (Schatlowski et al., 2008). Interestingly, CUC2 and CUC3 carry the H3K27me3 repressive mark. CUC2 shows this mark in the meristem and leaves, whereas CUC3 specifically carries the H3K27me3 mark in the leaves (Lafos et al., 2011). Thus, developmentally regulated deposition of repressive histone marks is likely to contribute to proper CUC2 and CUC3 expression.

Engelhorn et al. (2012) screened for genes expressed in the plant apex which were regulated by PRC1. They characterized the DEVELOPMENT-RELATED PCG TARGET IN THE APEX 4 (DPA4) gene, which encodes a transcriptional repressor containing a B3 DNA-binding domain. DPA4, like CUC genes, is expressed in the boundary domains of the meristem and leaf primordia. DPA4 negatively regulates CUC2 expression and, accordingly, dpa4 mutants show increased leaf serration, whereas a DPA4 overexpressor presents smooth leaves. Thus, DPA4 appears to be an upstream negative regulator of CUC2 expression.

\subsection{NAM/CUC3 CONTROL PLANT DEVELOPMENT VIA MODIFICATIONS OF THE CELLULAR BEHAVIOR}

Organ boundaries act both as frontiers and growth organizer centers (Aida and Tasaka, 2006). Boundaries cells display typically reduced growth activity, delimiting the frontier between different cell types. Besides this role in organ/tissue separation, boundaries participate in organ initiation and meristematic activity maintenance. Therefore, CUCs are likely to play different roles in controlling multiple aspects of plant growth and morphogenesis. Here, we focus on the effects downstream of CUCs, exploring the cellular effects dependent on CUCs, how they are achieved, and what molecular actors are involved (Figure 15.5).

\subsubsection{CUC-Dependent Cellular Effects}

Genetic analysis of cuc mutant combinations, coupled with morphologic analysis, suggest that $C U C 1 / 2 / 3$ repress growth in boundaries thus allowing organ separation (Aida et al., 1997; Aida et al., 1999; Takada et al., 2001; Vroemen et al., 2003). Growth integrates cell division and cell expansion parameters; therefore, reduced growth activity from cells localized at boundaries can be due to decreased cell division rate, reduced cell expansion, or both. Several pieces of work investigating various species report that cells located at boundaries display reduced cell division (Breuil-Broyer et al., 2004; Gaudin et al., 2000). However, experimental work linking cell proliferation and CUC transcription factors is scarce. In the wild-type Arabidopsis inflorescence meristem, floral primordia are formed 5-6 cells apart from each other (Heisler et al., 2005; Reddy et al., 2004). In the mir164abc triple-mutant, mature flowers are separated by roughly the same number of cells indicating that plant cell division in mir164abc is repressed between flowers during stem development. This correlates with local increase of CUC1 expression suggesting a function for CUC1 in controlling cell division (Sieber et al., 2007). To test this hypothesis, Sieber and coworkers ectopically expressed CUC1 and examined sepal cells. Sepal length was dramatically reduced in plants overexpressing CUC1, but the cell number per area unit was not different from the wild type suggesting that CUC1 plays a role in cell division regulation. Taken together these results indicate that CUCs act as growth antagonists through local repression of cell division.

Leaf development constitutes an excellent model to study cellular parameters controlled by CUC genes. By analogy with cellular mechanisms occurring at lateral organ primordia boundaries, CUC2 has been suggested to restrict growth of sinuses at the leaf margin (Nikovics et al., 2006). In contrast, CUC2 promotes tooth outgrowth via a non-cell-autonomous pathway involving auxin (Bilsborough et al., 2011; Kawamura et al., 2010). These opposing results highlight the fact that CUCs control cell proliferation in different ways to allow differential growth.

\subsubsection{How Does CUC Impact Cell Proliferation?}

In plants, cell proliferation depends on the action of phytohormones. BRs, for example, constitute a major class 
of polyhydroxysteroid hormones, structurally similar to steroid hormones in animals, promoting growth in various developmental processes (Mussig, 2005). BRs promote growth by controlling both cell elongation and cell division. BR-insensitive mutants display dwarf phenotypes, partially as a result of impaired mitotic activity (GonzalezGarcia et al., 2011; Zhiponova et al., 2013). The LATERAL ORGAN BOUNDARIES (LOB) gene negatively controls $\mathrm{BR}$ accumulation in boundaries, while BRs repress other boundary identity genes, such as CUC genes, in a feedback loop to control boundary formation (Section 15.3; Bell et al., 2012; Gendron et al., 2012). These studies reveal the fundamental role BRs play in boundary delimitation and link BR signaling to boundary identity genes.

Another hormone playing a key role in boundary formation is auxin. Spatiotemporal auxin accumulation relies on controlled expression and subcellular localization of auxin efflux transporters PIN1 (Friml et al., 2004; Okada et al., 1991). JAGGED LATERAL ORGAN (JLO), a boundary identity gene and member of the LATERAL ORGAN BOUNDARY DOMAIN (LBD) transcription factor family - to which LOB belongs - controls PIN expression (Bureau et al., 2010; Rast and Simon, 2012). CUC2 promotes auxin accumulation via an unknown PIN1-dependent mechanism in leaves and, in turn, auxin represses CUC2 expression forming a regulatory feedback loop. In silico models accounting for such a regulatory loop recapitulate wild-type leaf margin development and teeth formation patterns (Bilsborough et al., 2011).

Interestingly, BRs and auxins act synergistically to regulate photomorphogenesis by modulating AUXIN RESPONSE FACTOR2 (ARF2) activity of BR signaling components (Vert et al., 2008). Therefore, it is probable that the integrated action of these two hormones regulates boundary domain formation as well.

Although it is clear from the work described above that the CUC genes, auxins, and BRs play important roles in boundary delimitation, the underlying molecular mechanisms still need to be elucidated.

\subsubsection{CUC Direct Targets}

cuc mutant boundary phenotypes can be enhanced by mutations in several other genes, including transcription factors (Gomez-Mena and Sablowski, 2008; Lee et al., 2009; Lie et al., 2012), chromatin-remodeling factors (Kwon et al., 2006), and auxin flux regulators (Furutani et al., 2004). Taken together these studies show that CUC transcription factors cooperate with various biological processes to regulate boundary formation. Despite efforts to identify the molecular factors responsible for boundary delimitation, little is known about the regulatory network involved in this developmental process.

So far, only two CUC direct targets have been identified. Using rat glucocorticoid-receptor-inducible cell lines overexpressing CUC1, Takeda et al. (2011) showed that LIGHT-DEPENDENT SHORT HYPOCOTYL4 (LSH4) and its homolog LSH3 are directly activated by CUC1 in boundary cells. These genes encode proteins belonging to the ALOG family (Arabidopsis LSH1 and Oryza G1) which are predicted to bind DNA and modulate transcriptional activity (Iyer and Aravind, 2012). LSH3 (also known as OBO1; Cho and Zambryski, 2011) and LSH4 are located in the nuclei of boundary cells and, therefore, may play a role in boundary formation (Takeda et al., 2011). Constitutive LSH4 expression results in developmental defects such as inhibition of leaf growth and formation of ectopic meristems highlighting its potential role during plant development. Conversely, constitutive LSH4 expression cannot rescue the developmental defects of cuc1-cuc2 mutants, suggesting that other regulators act downstream of CUC1 to delimit boundaries.

\subsubsection{Other Regulators: KNOX, LFY, LAS}

Other regulators are known to act downstream of CUC transcription factors, but their molecular links are still missing. This is the case for KNOXI genes. Hibara et al. (2003) have shown that KNOXI genes such as STM and BREVIPEDICELLUS (BP) are ectopically expressed in Arabidopsis plants overexpressing CUC1. More generally, the accumulation of KNOXI/LFY-like transcripts is reduced in leaves when NAM/CUC3 genes are silenced (Blein et al., 2008). These results, together with the data presented in Section 15.4.3.1, reveal the existence of a feedforward regulatory loop between KNOXI/LFY-like genes and NAM/CUC3 genes during leaf development, which is likely to be conserved widely across eudicots. The $L A T$ ERAL SUPPRESSOR (LAS) gene encodes a member of the GAI, RGA, SCR (GRAS) family of putative transcription factors, which is expressed at the SAM boundary (Greb et al., 2003). LAS expression decreases when CUC activity is reduced suggesting that LAS acts downstream of CUC (Raman et al., 2008). Accordingly, the higher level of CUC mRNA accumulation in mir164abc mutants correlates with an increase in LAS expression.

\subsection{CONCLUSION}

Since their first identification almost 20 years ago, a wealth of data have been accumulated on NAM/CUC3 genes, establishing their central role in plant boundary formation. Fine analyses have shown a strong conservation of their function from species to species and in different organs of aerial parts, but have also underlined variations within this general trend. However, these conclusions are mostly based on genetic analyses. The challenge for the next years will be to reveal the molecular links, in particular, the genetic regulatory network between NAM/CUC3 transcription factors and boundary biology. 


\section{References}

Adam, H., Marguerettaz, M., Qadri, R., Adroher, B., Richaud, F., Collin, M., Thuillet, A.C., Vigouroux, Y., Laufs, P., Tregear, J.W., Jouannic, S., 2011. Divergent expression patterns of miR164 and CUP-SHAPED COTYLEDON genes in palms and other monocots: implication for the evolution of meristem function in angiosperms. Mol. Biol. Evol. $28,1439-1454$.

Aida, M., Tasaka, M., 2006. Morphogenesis and patterning at the organ boundaries in the higher plant shoot apex. Plant Mol. Biol. 60, 915-928.

Aida, M., Ishida, T., Fukaki, H., Fujisawa, H., Tasaka, M., 1997. Genes involved in organ separation in Arabidopsis: an analysis of the cupshaped cotyledon mutant. Plant Cell 9, 841-857.

Aida, M., Ishida, T., Tasaka, M., 1999. Shoot apical meristem and cotyledon formation during Arabidopsis embryogenesis: interaction among the CUP-SHAPED COTYLEDON and SHOOT MERISTEMLESS genes. Development 126, 1563-1570.

Aida, M., Vernoux, T., Furutani, M., Traas, J., Tasaka, M., 2002. Roles of PIN-FORMED1 and MONOPTEROS in pattern formation of the apical region of the Arabidopsis embryo. Development 129, 3965-3974.

Axtell, M.J., Bartel, D.P., 2005. Antiquity of microRNAs and their targets in land plants. Plant Cell 17, 1658-1673.

Baker, C.C., Sieber, P., Wellmer, F., Meyerowitz, E.M., 2005. The early extra petals1 mutant uncovers a role for microRNA miR164c in regulating petal number in Arabidopsis. Curr. Biol. 15, 303-315.

Bell, E.M., Lin, W.C., Husbands, A.Y., Yu, L., Jaganatha, V., Jablonska, B., Mangeon, A., Neff, M.M., Girke, T., Springer, P.S., 2012. Arabidopsis LATERAL ORGAN BOUNDARIES negatively regulates brassinosteroid accumulation to limit growth in organ boundaries. Proc. Natl. Acad. Sci. USA 109, 21146-21151.

Belles-Boix, E., Hamant, O., Witiak, S.M., Morin, H., Traas, J., Pautot, V., 2006. KNAT6: an Arabidopsis homeobox gene involved in meristem activity and organ separation. Plant Cell 18, 1900-1907.

Ben-Gera, H., Shwartz, I., Shao, M.R., Shani, E., Estelle, M., Ori, N., 2012. ENTIRE and GOBLET promote leaflet development in tomato by modulating auxin response. Plant J. 70, 903-915.

Berger, Y., Harpaz-Saad, S., Brand, A., Melnik, H., Sirding, N., Alvarez, J.P., Zinder, M., Samach, A., Eshed, Y., Ori, N., 2009. The NACdomain transcription factor GOBLET specifies leaflet boundaries in compound tomato leaves. Development 136, 823-832.

Bharathan, G., Goliber, T.E., Moore, C., Kessler, S., Pham, T., Sinha, N.R., 2002. Homologies in leaf form inferred from KNOXI gene expression during development. Science 296, 1858-1860.

Bilsborough, G.D., Runions, A., Barkoulas, M., Jenkins, H.W., Hasson, A., Galinha, C., Laufs, P., Hay, A., Prusinkiewicz, P., Tsiantis, M., 2011. Model for the regulation of Arabidopsis thaliana leaf margin development. Proc. Natl. Acad. Sci. USA 108, 3424-3429.

Blein, T., Pulido, A., Vialette-Guiraud, A., Nikovics, K., Morin, H., Hay, A., Johansen, I.E., Tsiantis, M., Laufs, P., 2008. A conserved molecular framework for compound leaf development. Science 322, 1835-1839.

Blein, T., Hasson, A., Laufs, P., 2010. Leaf development: what it needs to be complex. Curr. Opin. Plant Biol. 13, 75-82.

Brand, A., Shirding, N., Shleizer, S., Ori, N., 2007. Meristem maintenance and compound-leaf patterning utilize common genetic mechanisms in tomato. Planta 226, 941-951.

Breuil-Broyer, S., Morel, P., De Almeida-Engler, J., Coustham, V., Negrutiu, I., Trehin, C., 2004. High-resolution boundary analysis during Arabidopsis thaliana flower development. Plant J. 38, 182-192.

Bureau, M., Rast, M.I., Illmer, J., Simon, R., 2010. JAGGED LATERAL ORGAN (JLO) controls auxin dependent patterning during development of the Arabidopsis embryo and root. Plant Mol. Biol. 74, 479-491.

Cheng, X., Peng, J., Ma, J., Tang, Y., Chen, R., Mysore, K.S., Wen, J., 2012. NO APICAL MERISTEM (MtNAM) regulates floral organ identity and lateral organ separation in Medicago truncatula. New Phytol. $195,71-84$.
Cho, E., Zambryski, P.C., 2011. ORGAN BOUNDARY1 defines a gene expressed at the junction between the shoot apical meristem and lateral organs. Proc. Natl. Acad. Sci. USA 108, 2154-2159.

Corpet, F., 1988. Multiple sequence alignment with hierarchical clustering. Nucleic Acids Res. 16, 10881-10890.

Duval, M., Hsieh, T.F., Kim, S.Y., Thomas, T.L., 2002. Molecular characterization of AtNAM: a member of the Arabidopsis NAC domain superfamily. Plant Mol. Biol. 50, 237-248.

Engelhorn, J., Reimer, J.J., Leuz, I., Gobel, U., Huettel, B., Farrona, S., Turck, F., 2012. Development-related PcG target in the apex 4 controls leaf margin architecture in Arabidopsis thaliana. Development $139,2566-2575$.

Ernst, H.A., Nina Olsen, A., Skriver, K., Larsen, S., Lo Leggio, L., 2004. Structure of the conserved domain of ANAC, a member of the NAC family of transcription factors. EMBO Rep. 5, 297-303.

Fang, Y., You, J., Xie, K., Xie, W., Xiong, L., 2008. Systematic sequence analysis and identification of tissue-specific or stress-responsive genes of NAC transcription factor family in rice. Mol. Genet. Genomics 280, 547-563.

Finet, C., Timme, R.E., Delwiche, C.F., Marletaz, F., 2010. Multigene phylogeny of the green lineage reveals the origin and diversification of land plants. Curr. Biol. 20, 2217-2222.

Friml, J., Vieten, A., Sauer, M., Weijers, D., Schwarz, H., Hamann, T., Offringa, R., Jurgens, G., 2003. Efflux-dependent auxin gradients establish the apical-basal axis of Arabidopsis. Nature 426, 147-153.

Friml, J., Yang, X., Michniewicz, M., Weijers, D., Quint, A., Tietz, O., Benjamins, R., Ouwerkerk, P.B., Ljung, K., Sandberg, G., Hooykaas, P.J., Palme, K., Offringa, R., 2004. A PINOID-dependent binary switch in apical-basal PIN polar targeting directs auxin efflux. Science 306, 862-865.

Furutani, M., Vernoux, T., Traas, J., Kato, T., Tasaka, M., Aida, M., 2004. PIN-FORMED1 and PINOID regulate boundary formation and cotyledon development in Arabidopsis embryogenesis. Development 131, 5021-5030.

Galbiati, F., Sinha Roy, D., Simonini, S., Cucinotta, M., Ceccato, L., Cuesta, C., Simaskova, M., Benkova, E., Kamiuchi, Y., Aida, M., Weijers, D., Simon, R., Masiero, S., Colombo, L., 2013. An integrative model of the control of ovule primordia formation. Plant J. $76,446-455$.

Gaudin, V., Lunness, P.A., Fobert, P.R., Towers, M., Riou-Khamlichi, C., Murray, J.A., Coen, E., Doonan, J.H., 2000. The expression of D-cyclin genes defines distinct developmental zones in snapdragon apical meristems and is locally regulated by the cycloidea gene. Plant Physiol. 122, 1137-1148.

Gendron, J.M., Liu, J.S., Fan, M., Bai, M.Y., Wenkel, S., Springer, P.S., Barton, M.K., Wang, Z.Y., 2012. Brassinosteroids regulate organ boundary formation in the shoot apical meristem of Arabidopsis. Proc. Natl. Acad. Sci. USA 109, 21152-21157.

Gomez-Mena, C., Sablowski, R., 2008. ARABIDOPSIS THALIANA HOMEOBOX GENE1 establishes the basal boundaries of shoot organs and controls stem growth. Plant Cell 20, 2059-2072.

Gonzalez-Garcia, M.P., Vilarrasa-Blasi, J., Zhiponova, M., Divol, F., Mora-Garcia, S., Russinova, E., Cano-Delgado, A.I., 2011. Brassinosteroids control meristem size by promoting cell cycle progression in Arabidopsis roots. Development 138, 849-859.

Grbic, V., Bleecker, A.B., 2000. Axillary meristem development in Arabidopsis thaliana. Plant J. 21, 215-223.

Greb, T., Clarenz, O., Schafer, E., Muller, D., Herrero, R., Schmitz, G., Theres, K., 2003. Molecular analysis of the LATERAL SUPPRESSOR gene in Arabidopsis reveals a conserved control mechanism for axillary meristem formation. Genes Dev. 17, 1175-1187.

Guo, H.S., Xie, Q., Fei, J.F., Chua, N.H., 2005. MicroRNA directs mRNA cleavage of the transcription factor NAC1 to downregulate auxin signals for Arabidopsis lateral root development. Plant Cell 17, 1376-1386. 
Hamant, O., Pautot, V., 2010. Plant development: a TALE story. C.R. Biol. 333, 371-381.

Hasson, A., Plessis, A., Blein, T., Adroher, B., Grigg, S., Tsiantis, M., Boudaoud, A., Damerval, C., Laufs, P., 2011. Evolution and diverse roles of the CUP-SHAPED COTYLEDON genes in Arabidopsis leaf development. Plant Cell 23, 54-68.

Hay, A., Tsiantis, M., 2006. The genetic basis for differences in leaf form between Arabidopsis thaliana and its wild relative Cardamine hirsuta. Nat. Genet. 38, 942-947.

Hay, A., Tsiantis, M., 2009. A KNOX family TALE. Curr. Opin. Plant Biol. 12, 593-598.

Hay, A., Barkoulas, M., Tsiantis, M., 2006. ASYMMETRIC LEAVES1 and auxin activities converge to repress BREVIPEDICELLUS expression and promote leaf development in Arabidopsis. Development 133, 3955-3961.

Heisler, M.G., Ohno, C., Das, P., Sieber, P., Reddy, G.V., Long, J.A., Meyerowitz, E.M., 2005. Patterns of auxin transport and gene expression during primordium development revealed by live imaging of the Arabidopsis inflorescence meristem. Curr. Biol. 15, 1899-1911.

Hibara, K., Takada, S., Tasaka, M., 2003. CUC1 gene activates the expression of SAM-related genes to induce adventitious shoot formation. Plant J. 36, 687-696.

Hibara, K., Karim, M.R., Takada, S., Taoka, K., Furutani, M., Aida, M., Tasaka, M., 2006. Arabidopsis CUP-SHAPED COTYLEDON3 regulates postembryonic shoot meristem and organ boundary formation. Plant Cell 18, 2946-2957.

Hofer, J., Turner, L., Hellens, R., Ambrose, M., Matthews, P., Michael, A., Ellis, N., 1997. UNIFOLIATA regulates leaf and flower morphogenesis in pea. Curr. Biol. 7, 581-587.

Hu, R., Qi, G., Kong, Y., Kong, D., Gao, Q., Zhou, G., 2010. Comprehensive analysis of NAC domain transcription factor gene family in Populus trichocarpa. BMC Plant Biol. 10, 145.

Huang, T., Lopez-Giraldez, F., Townsend, J.P., Irish, V.F., 2012. RBE controls microRNA164 expression to effect floral organogenesis. Development 139, 2161-2169.

Ishida, T., Aida, M., Takada, S., Tasaka, M., 2000. Involvement of CUPSHAPED COTYLEDON genes in gynoecium and ovule development in Arabidopsis thaliana. Plant Cell Physiol. 41, 60-67.

Iyer, L.M., Aravind, L., 2012. ALOG domains: provenance of plant homeotic and developmental regulators from the DNA-binding domain of a novel class of DIRS1-type retroposons. Biol. Direct 7, 39 .

Jasinski, S., Vialette-Guiraud, A.C., Scutt, C.P., 2010. The evolutionarydevelopmental analysis of plant microRNAs. Philos. Trans. R. Soc. Lond. B Biol. Sci. 365, 469-476.

Jensen, M.K., Kjaersgaard, T., Nielsen, M.M., Galberg, P., Petersen, K., O'Shea, C., Skriver, K., 2010. The Arabidopsis thaliana NAC transcription factor family: structure-function relationships and determinants of ANAC019 stress signalling. Biochem. J. 426, 183-196.

Jerzmanowski, A., 2007. SWI/SNF chromatin remodeling and linker histones in plants. Biochim. Biophys. Acta 1769, 330-345.

Kamiuchi, Y., Yamamoto, K., Furutani, M., Tasaka, M., Aida, M., 2014. The CUC1 and CUC2 genes promote carpel margin meristem formation during Arabidopsis gynoecium development. Front. Plant Sci. 5, 165.

Kawamura, E., Horiguchi, G., Tsukaya, H., 2010. Mechanisms of leaf tooth formation in Arabidopsis. Plant J. 62, 429-441.

Keller, T., Abbott, J., Moritz, T., Doerner, P., 2006. Arabidopsis REGULATOR OF AXILLARY MERISTEMS1 controls a leaf axil stem cell niche and modulates vegetative development. Plant Cell 18, 598-611.

Kim, T.W., Wang, Z.Y., 2010. Brassinosteroid signal transduction from receptor kinases to transcription factors. Annu. Rev. Plant Biol. 61, 681-704.

Kim, J.H., Woo, H.R., Kim, J., Lim, P.O., Lee, I.C., Choi, S.H., Hwang, D., Nam, H.G., 2009. Trifurcate feed-forward regulation of agedependent cell death involving miR164 in Arabidopsis. Science 323, 1053-1057.
Koyama, T., Furutani, M., Tasaka, M., Ohme-Takagi, M., 2007. TCP transcription factors control the morphology of shoot lateral organs via negative regulation of the expression of boundary-specific genes in Arabidopsis. Plant Cell 19, 473-484.

Koyama, T., Mitsuda, N., Seki, M., Shinozaki, K., Ohme-Takagi, M., 2010. TCP transcription factors regulate the activities of ASYMMETRIC LEAVES1 and miR164, as well as the auxin response, during differentiation of leaves in Arabidopsis. Plant Cell 22, 3574-3588.

Krizek, B.A., Lewis, M.W., Fletcher, J.C., 2006. RABBIT EARS is a secondwhorl repressor of AGAMOUS that maintains spatial boundaries in Arabidopsis flowers. Plant J. 45, 369-383.

Kwon, C.S., Hibara, K., Pfluger, J., Bezhani, S., Metha, H., Aida, M., Tasaka, M., Wagner, D., 2006. A role for chromatin remodeling in regulation of CUC gene expression in the Arabidopsis cotyledon boundary. Development 133, 3223-3230.

Lafos, M., Kroll, P., Hohenstatt, M.L., Thorpe, F.L., Clarenz, O., Schubert, D., 2011. Dynamic regulation of H3K27 trimethylation during Arabidopsis differentiation. PLoS Genet. 7, e1002040.

Larsson, E., Sundstrom, J.F., Sitbon, F., Von Arnold, S., 2012. Expression of PaNAC01, a Picea abies CUP-SHAPED COTYLEDON orthologue, is regulated by polar auxin transport and associated with differentiation of the shoot apical meristem and formation of separated cotyledons. Ann. Bot. 110, 923-934.

Larue, C.T., Wen, J., Walker, J.C., 2009. A microRNA-transcription factor module regulates lateral organ size and patterning in Arabidopsis. Plant J. 58, 450-463.

Laufs, P., Peaucelle, A., Morin, H., Traas, J., 2004. MicroRNA regulation of the CUC genes is required for boundary size control in Arabidopsis meristems. Development 131, 4311-4322.

Lee, D.K., Geisler, M., Springer, P.S., 2009. LATERAL ORGAN FUSION1 and LATERAL ORGAN FUSION2 function in lateral organ separation and axillary meristem formation in Arabidopsis. Development 136, 2423-2432.

Li, X.G., Su, Y.H., Zhao, X.Y., Li, W., Gao, X.Q., Zhang, X.S., 2010. Cytokinin overproduction-caused alteration of flower development is partially mediated by CUC2 and CUC3 in Arabidopsis. Gene 450, 109-120.

Li, Z., Peng, J., Wen, X., Guo, H., 2013. Ethylene-insensitive3 is a senescence-associated gene that accelerates age-dependent leaf senescence by directly repressing miR164 transcription in Arabidopsis. Plant Cell 25, 3311-3328.

Lie, C., Kelsom, C., Wu, X., 2012. WOX2 and STIMPY-LIKE/WOX8 promote cotyledon boundary formation in Arabidopsis. Plant J. 72, 674-682.

Lindemose, S., Jensen, M.K., De Velde, J.V., O'Shea, C., Heyndrickx, K.S., Workman, C.T., Vandepoele, K., Skriver, K., Masi, F.D., 2014. A DNA-binding-site landscape and regulatory network analysis for NAC transcription factors in Arabidopsis thaliana. Nucleic Acids Res. 42, 7681-7693.

Mallory, A.C., Dugas, D.V., Bartel, D.P., Bartel, B., 2004. MicroRNA regulation of NAC-domain targets is required for proper formation and separation of adjacent embryonic, vegetative, and floral organs. Curr. Biol. 14, 1035-1046.

Marhavy, P., Duclercq, J., Weller, B., Feraru, E., Bielach, A., Offringa, R., Friml, J., Schwechheimer, C., Murphy, A., Benkova, E., 2014. Cytokinin controls polarity of PIN1-dependent auxin transport during lateral root organogenesis. Curr. Biol. 24, 1031-1037.

Martin-Trillo, M., Cubas, P., 2009. TCP genes: a family snapshot ten years later. Trends Plant Sci. 15, 31-39.

Muller, D., Schmitz, G., Theres, K., 2006. Blind homologous R2R3 Myb genes control the pattern of lateral meristem initiation in Arabidopsis. Plant Cell 18, 586-597.

Mussig, C., 2005. Brassinosteroid-promoted growth. Plant Biol. 7, $110-117$.

Nahar, M.A., Ishida, T., Smyth, D.R., Tasaka, M., Aida, M., 2012. Interactions of CUP-SHAPED COTYLEDON and SPATULA genes control 
carpel margin development in Arabidopsis thaliana. Plant Cell Physiol. $53,1134-1143$.

Nakano, T., Kimbara, J., Fujisawa, M., Kitagawa, M., Ihashi, N., Maeda, H., Kasumi, T., Ito, Y., 2012. MACROCALYX and JOINTLESS interact in the transcriptional regulation of tomato fruit abscission zone development. Plant Physiol. 158, 439-450.

Nakano, T., Fujisawa, M., Shima, Y., Ito, Y., 2013. Expression profiling of tomato pre-abscission pedicels provides insights into abscission zone properties including competence to respond to abscission signals. BMC Plant Biol. 13, 40.

Nakano, T., Fujisawa, M., Shima, Y., Ito, Y., 2014. The AP2/ERF transcription factor SIERF52 functions in flower pedicel abscission in tomato. J. Exp. Bot. 65, 3111-3119.

Nikovics, K., Blein, T., Peaucelle, A., Ishida, T., Morin, H., Aida, M., Laufs, P., 2006. The balance between the MIR164A and CUC2 genes controls leaf margin serration in Arabidopsis. Plant Cell 18, 2929-2945.

Okada, K., Ueda, J., Komaki, M.K., Bell, C.J., Shimura, Y., 1991. Requirement of the auxin polar transport system in early stages of Arabidopsis floral bud formation. Plant Cell 3, 677-684.

Olsen, A.N., Ernst, H.A., Lo Leggio, L., Skriver, K., 2005. DNA-binding specificity and molecular functions of NAC transcription factors. Plant Sci. 169, 785-797.

Ooka, H., Satoh, K., Doi, K., Nagata, T., Otomo, Y., Murakami, K., Matsubara, K., Osato, N., Kawai, J., Carninci, P., Hayashizaki, Y., Suzuki, K., Kojima, K., Takahara, Y., Yamamoto, K., Kikuchi, S., 2003. Comprehensive analysis of NAC family genes in Oryza sativa and Arabidopsis thaliana. DNA Res. 10, 239-247.

Peaucelle, A., Morin, H., Traas, J., Laufs, P., 2007. Plants expressing a miR164-resistant CUC2 gene reveal the importance of post-meristematic maintenance of phyllotaxy in Arabidopsis. Development 134, 1045-1050.

Pinheiro, G.L., Marques, C.S., Costa, M.D., Reis, P.A., Alves, M.S., Carvalho, C.M., Fietto, L.G., Fontes, E.P., 2009. Complete inventory of soybean NAC transcription factors: sequence conservation and expression analysis uncover their distinct roles in stress response. Gene 444, 10-23.

Pulido, A., Laufs, P., 2010. Co-ordination of developmental processes by small RNAs during leaf development. J. Exp. Bot. 61, 1277-1291.

Raman, S., Greb, T., Peaucelle, A., Blein, T., Laufs, P., Theres, K., 2008. Interplay of miR164, CUP-SHAPED COTYLEDON genes and LATERAL SUPPRESSOR controls axillary meristem formation in Arabidopsis thaliana. Plant J. 55, 65-76.

Rast, M.I., Simon, R., 2012. Arabidopsis JAGGED LATERAL ORGANS acts with ASYMMETRIC LEAVES2 to coordinate KNOX and PIN expression in shoot and root meristems. Plant Cell 24, 2917-2933.

Reddy, G.V., Heisler, M.G., Ehrhardt, D.W., Meyerowitz, E.M., 2004. Real-time lineage analysis reveals oriented cell divisions associated with morphogenesis at the shoot apex of Arabidopsis thaliana. Development 131, 4225-4237.

Reinhardt, D., Pesce, E.R., Stieger, P., Mandel, T., Baltensperger, K., Bennett, M., Traas, J., Friml, J., Kuhlemeier, C., 2003. Regulation of phyllotaxis by polar auxin transport. Nature 426, 255-260.

Roudier, F., Gissot, L., Beaudoin, F., Haslam, R., Michaelson, L., Marion, J., Molino, D., Lima, A., Bach, L., Morin, H., Tellier, F., Palauqui, J.C., Bellec, Y., Renne, C., Miquel, M., Dacosta, M., Vignard, J., Rochat, C., Markham, J.E., Moreau, P., Napier, J., Faure, J.D., 2010. Very-longchain fatty acids are involved in polar auxin transport and developmental patterning in Arabidopsis. Plant Cell 22, 364-375.

Schatlowski, N., Creasey, K., Goodrich, J., Schubert, D., 2008. Keeping plants in shape: polycomb-group genes and histone methylation. Semin. Cell Dev. Biol. 19, 547-553.

Schwab, R., Palatnik, J.F., Riester, M., Schommer, C., Schmid, M., Weigel, D., 2005. Specific effects of microRNAs on the plant transcriptome. Dev. Cell 8, 517-527.
Shen, H., Yin, Y., Chen, F., Xu, Y., Dixon, R.A., 2009. A bioinformatic analysis of NAC genes for plant cell wall development in relation to lignocellulosic bioenergy production. Bioenerg. Res. 2, 217-232.

Sieber, P., Wellmer, F., Gheyselinck, J., Riechmann, J.L., Meyerowitz, E.M., 2007. Redundancy and specialization among plant microRNAs: role of the MIR164 family in developmental robustness. Development 134, 1051-1060.

Souer, E., Van Houwelingen, A., Kloos, D., Mol, J., Koes, R., 1996. The No Apical Meristem gene of petunia is required for pattern formation in embryos and flower and is expressed at meristem and primordia boundaries. Cell 85, 159-170.

Spinelli, S.V., Martin, A.P., Viola, I.L., Gonzalez, D.H., Palatnik, J.F., 2011. A mechanistic link between STM and CUC1 during Arabidopsis development. Plant Physiol. 156, 1894-1904.

Takada, S., Hibara, K., Ishida, T., Tasaka, M., 2001. The CUP-SHAPED COTYLEDON1 gene of Arabidopsis regulates shoot apical meristem formation. Development 128, 1127-1135.

Takeda, S., Hanano, K., Kariya, A., Shimizu, S., Zhao, L., Matsui, M., Tasaka, M., Aida, M., 2011. CUP-SHAPED COTYLEDON1 transcription factor activates the expression of LSH4 and LSH3, two members of the ALOG gene family, in shoot organ boundary cells. Plant J. 66, 1066-1077.

Taoka, K., Yanagimoto, Y., Daimon, Y., Hibara, K., Aida, M., Tasaka, M., 2004. The NAC domain mediates functional specificity of CUPSHAPED COTYLEDON proteins. Plant J. 40, 462-473.

Todesco, M., Balasubramanian, S., Cao, J., Ott, F., Sureshkumar, S., Schneeberger, K., Meyer, R.C., Altmann, T., Weigel, D., 2012. Natural variation in biogenesis efficiency of individual Arabidopsis thaliana microRNAs. Curr. Biol. 22, 166-170.

Tran, L.S., Nakashima, K., Sakuma, Y., Simpson, S.D., Fujita, Y., Maruyama, K., Fujita, M., Seki, M., Shinozaki, K., YamaguchiShinozaki, K., 2004. Isolation and functional analysis of Arabidopsis stress-inducible NAC transcription factors that bind to a droughtresponsive cis-element in the early responsive to dehydration stress 1 promoter. Plant Cell 16, 2481-2498.

Uberti-Manassero, N.G., Lucero, L.E., Viola, I.L., Vegetti, A.C., Gonzalez, D.H., 2012. The class I protein AtTCP15 modulates plant development through a pathway that overlaps with the one affected by CIN-like TCP proteins. J. Exp. Bot. 63, 809-823.

Vernoux, T., Kronenberger, J., Grandjean, O., Laufs, P., Traas, J., 2000. PIN-FORMED 1 regulates cell fate at the periphery of the shoot apical meristem. Development 127, 5157-5165.

Vert, G., Walcher, C.L., Chory, J., Nemhauser, J.L., 2008. Integration of auxin and brassinosteroid pathways by Auxin Response Factor 2. Proc. Natl. Acad. Sci. USA 105, 9829-9834.

Vialette-Guiraud, A.C., Adam, H., Finet, C., Jasinski, S., Jouannic, S., Scutt, C.P., 2011. Insights from ANA-grade angiosperms into the early evolution of CUP-SHAPED COTYLEDON genes. Ann. Bot. $107,1511-1519$.

Vroemen, C.W., Mordhorst, A.P., Albrecht, C., Kwaaitaal, M.A., De Vries, S.C., 2003. The CUP-SHAPED COTYLEDON3 gene is required for boundary and shoot meristem formation in Arabidopsis. Plant Cell $15,1563-1577$.

Wang, Z., Chen, J., Weng, L., Li, X., Cao, X., Hu, X., Luo, D., Yang, J., 2013. Multiple components are integrated to determine leaf complexity in Lotus japonicus. J. Integr. Plant Biol. 55, 419-433.

Wang, Q., Kohlen, W., Rossmann, S., Vernoux, T., Theres, K., 2014a. Auxin depletion from the leaf axil conditions competence for axillary meristem formation in Arabidopsis and tomato. Plant Cell 26, 2068-2079.

Wang, Y., Wang, J., Shi, B., Yu, T., Qi, J., Meyerowitz, E.M., Jiao, Y., 2014 b. The stem cell niche in leaf axils is established by auxin and cytokinin in Arabidopsis. Plant Cell 26, 2055-2067.

Weir, I., Lu, J., Cook, H., Causier, B., Schwarz-Sommer, Z., Davies, B., 2004. CUPULIFORMIS establishes lateral organ boundaries in Antirrhinum. Development 131, 915-922. 
Welner, D.H., Lindemose, S., Grossmann, J.G., Mollegaard, N.E., Olsen, A.N., Helgstrand, C., Skriver, K., Lo Leggio, L., 2012. DNA binding by the plant-specific NAC transcription factors in crystal and solution: a firm link to WRKY and GCM transcription factors. Biochem. J. 444, 395-404.

Winter, C.M., Austin, R.S., Blanvillain-Baufume, S., Reback, M.A., Monniaux, M., Wu, M.F., Sang, Y., Yamaguchi, A., Yamaguchi, N., Parker, J.E., Parcy, F., Jensen, S.T., Li, H., Wagner, D., 2011. LEAFY target genes reveal floral regulatory logic, cis motifs, and a link to biotic stimulus response. Dev. Cell 20, 430-443.

Xu, Z.Y., Kim, S.Y., Hyeon Do, Y., Kim, D.H., Dong, T., Park, Y., Jin, J.B., Joo, S.H., Kim, S.K., Hong, J.C., Hwang, D., Hwang, I., 2013. The Arabidopsis NAC transcription factor ANAC096 cooperates with
bZIP-type transcription factors in dehydration and osmotic stress responses. Plant Cell 25, 4708-4724.

Zhiponova, M.K., Vanhoutte, I., Boudolf, V., Betti, C., Dhondt, S., Coppens, F., Mylle, E., Maes, S., Gonzalez-Garcia, M.P., Cano-Delgado, A.I., Inze, D., Beemster, G.T., De Veylder, L., Russinova, E., 2013. Brassinosteroid production and signaling differentially control cell division and expansion in the leaf. New Phytol. 197, 490-502.

Zhu, T., Nevo, E., Sun, D., Peng, J., 2012. Phylogenetic analyses unravel the evolutionary history of NAC proteins in plants. Evolution 66, 1833-1848.

Zimmermann, R., Werr, W., 2005. Pattern formation in the monocot embryo as revealed by NAM and CUC3 orthologues from Zea mays L. Plant Mol. Biol. 58, 669-685. 